\title{
REACTION OF BRAZILIAN COTTON GENOTYPES TO WHITE MOLD DEPENDS ON PATHOGEN AGGRESSIVENESS AND INCUBATION CONDITIONS
}

\author{
REAÇÃO DE GENÓTIPOS BRASILEIROS DE ALGODOEIRO AO MOFO BRANCO \\ DEPENDE DA AGRESSIVIDADE DO PATÓGENO E DAS CONDIÇÕES DE \\ INCUBAÇÃO
}

\author{
Jeferson Rodrigo PESTANA ${ }^{\text {; }}$ Tâmara Prado de MORAIS ${ }^{1}$; Ana Paula Oliveira NOGUEIRA² \\ Fernando Cezar JULIATTI ${ }^{1,3}$ \\ 1. Institute of Agricultural Sciences, Federal University of Uberlândia, Uberlândia, MG, Brazil. jeferson_pestana@yahoo.com.br, 2. \\ Institute of Genetics and Biochemistry, Federal University of Uberlândia, Uberlândia, MG, Brazil. 3. Pesquisador 1D pelo \\ CNPq.Professor Titular da UFU. juliatti@ufu.br.
}

\begin{abstract}
The expansion of cotton crop into irrigated and high lands of Brazilian Cerrado, despite the possibility of increasing fiber yield, led to the occurrence of diseases previously considered secondary, such as white mold [Sclerotinia sclerotiorum (Lib.) de Bary]. Host genetic resistance is of extreme importance in integrated strategies to manage this disease. Resistance of Brazilian cotton genotypes, challenged with different strains of S. sclerotiorum, under two incubation conditions for disease progress was evaluated. In addition, possible correlation between oxalic acid and straw test methods to rank the genotypes was evaluated. Artificial inoculation was done when cotton plants reached the $\mathrm{V}_{2}$ phenological stage with fungi isolated from naturally infected soybean $(\mathrm{ScS})$ or cotton $(\mathrm{ScC})$ commercial crops. Control plants were inoculated with culture medium. After inoculation, plants were kept for one week either in a growth chamber or in greenhouse and evaluated for disease symptoms and severity. The oxalic acid test consisted of stem submersion of rootless cotton plants in a 2-cm layer of 20 or $40 \mathrm{mM}$ solutions for 20,44 or $68 \mathrm{~h}$. A wilting scale was used to distinguish genotype's sensibility to the acid. The data were submitted to individual, joint, and multivariate analysis, grouping cotton genotypes by the Scott-Knott's test $(\mathrm{p}<0.05)$, the hierarchical UPGMA and the non-hierarchical Tocher methods. Difference in aggressiveness between strains was identified, in which $\mathrm{ScC}$ led to greater disease severity. This result suggests a possible physiological specialization of S. sclerotiorum to different hosts. It was observed that the growth chamber environment provided more adequate conditions for $S$. sclerotiorum infection, thus allowing better selection of resistant cotton genotypes. UPGMA and Tocher grouping methods further confirmed that the evaluated genotypes differ from each other in resistance to white mold. No correlation between oxalic acid and straw test methods was observed.
\end{abstract}

KEYWORDS: Gossypium hirsutum L. Sclerotinia sclerotiorum. Genetic diversity. Physiological specialization.

\section{INTRODUCTION}

Upland cotton (Gossypium hirsutum L.) is one of the main crops domesticated by man (BELTRÃO; AZEVEDO, 2008), cultivated to supply fibers. Among the several diseases affecting this crop, white mold, caused by the fungus Sclerotinia sclerotiorum (Lib.) de Bary, is becoming more important in Brazil, the fifth greatest producer and responsible for $10.5 \%$ of global exportation of cotton fiber (SUASSUNA; COUTINHO, 2007; SUASSUNA, 2012; ABRAPA, 2017). Since its first report in 1996 in the county of Paracatu (state of Minas Gerais) (CHARCHAR; ANJOS; OSSIPI, 1999), the disease became widespread in crops under central pivot and in high altitude areas, due to cotton susceptibility and favorable environmental conditions for pathogen development, such as mild temperatures $\left(18-25^{\circ} \mathrm{C}\right)$, high air relative moisture $(>90 \%)$ and altitudes above $800 \mathrm{~m}$ (ABAWI;
GROGAN, 1979; BOLAND; HALL, 1994; CHITARRA, 2008).

Symptomatic cotton plants present wilt, necrosis and rotting of stem, bolls, petioles and leaves. Whitish fungal mycelium can be found inside the bolls, with the sclerotia, dark colored resistance structures of irregular shape (CHARCHAR; ANJOS; OSSIPI, 1999; CHITARRA, 2007). Disease incidence and severity in the field can affect up to $30 \%$ of the crop production (SNA, 2014), with impact of up to $\$ 11.52$ billion dollars. In this scenario, white mold has become detrimental to cotton cropping in Brazil, demanding constant attention from the farmer for proper management when the pathogen is found in the area (CHARCHAR; ANJOS; OSSIPI, 1999).

Among the principles of plant protection, the use of cultivars with genetic resistance is considered as the best strategy to avoid crop losses due to diseases. Moreover, it presents low cost and 
is environmentally sound due to the mitigation of pesticide spraying (SABATO; TEIXEIRA, 2015). The resistance mechanisms against white mold are associated both to morphological and to physiological characteristics of the host plant. Such mechanisms include barriers against pathogen penetration and, or, colonization (lignin deposition, tylose formation) and compounds able to suppress fungal development (phytoalexins, phenolic compounds, oxygen reactive species) (RODRIGUES et al., 2007; SCHWAN-ESTRADA; STANGARLIN; PASCHOLATI, 2008; ABOELYOUSR; HASHEM; ALI, 2009; STANGARLIN et al., 2011; FREI, 2013). Although genetic resistance can be extremely important for integrated disease management, there are few studies related to the interaction cotton-Sclerotinia (CHITARRA, 2007). There are proteomics, metabolomics and transcriptomics reports of the interactions Sclerotinia-Glycine max (L.) Merrill, SclerotiniaPhaseolus vulgaris L., Sclerotinia-Helianthus annuus L. and Sclerotinia-Brassica napus L. (PELUFFO et al., 2010; GARG et al., 2013; OLIVEIRA et al., 2015; CAO; XU; CAI, 2016; JOSHI et al., 2016a; WU et al., 2016). Even the selection of genes and genotypes resistant to the fungus overlook cotton while including alfalfa (PRATT; ROWE, 1991), peanut (AKEM; MELOUK; SMITH, 1992), sunflower (ACHBANI; DE LABROUHE; VEAR, 1994; BALDINI et al., 2002; DAVAR et al., 2011), lentil (AKEM; BELLAR; BAYAA, 2006), peas (PORTER; HOHEISEL; COFFMAN, 2009), okra (FISCHER et al., 2014), canola (AHMADIFAR; DALIL, 2013; WU et al., 2013; JOSHI et al., 2016b), common beans (LEITE, 2014; ABREU, 2016) and soybeans (GARCIA; JULIATTI, 2012; BASTIEN; SONAH; BELZILE, 2014; JULIATTI et al., 2014; IQUIRA; HUMIRA; FRANÇOIS, 2015; CASTRO et al., 2016; WEI et al., 2017).

Most studies are done with inoculation of host plants using ascospore suspension of $S$. sclerotiorum (GARG et al., 2010; PELUFFO et al., 2010; DAVIDSON et al., 2016) or fungal mycelia disks (WEGULO; YANG; MARTINSON, 1998; TERÁN et al., 2006; GARCIA; JULIATTI 2012; WU et al., 2013, 2016; OLIVEIRA et al., 2015; CASTRO et al., 2016; CAO; XU; CAI, 2016; JOSHI et al., 2016a, b; WEI et al., 2017). Alternatively, genotypes can be characterized according to their sensitivity to a solution of oxalic acid. This indirect method is faster, cheaper and less labor intensive, and has been successfully used in common beans, soybeans and sunflower (WEGULO; YANG; MARTINSON, 1998; KOLKMAN; KELLY, 2000; ANTÔNIO et al., 2008; HÜLLER et al., 2016). The potential of its use in cotton still has to be elucidated.

Presently, the scarcity of studies about the interaction Sclerotinia-cotton leave cotton farmers unsupported about recommendation of resistant cultivars for integrated management of white mold. Thus, this study evaluated resistance of Brazilian cotton genotypes to infection by $S$. sclerotiorum. Also, possible differences in aggressiveness of fungal strains (originally isolated from cotton or soybean plants), that could affect the process of selecting resistant cultivars, as well as the incubation environment for inoculated plants were studied, and the efficacy of the oxalic acid method for the evaluation of cotton resistance to white mold was analyzed.

\section{MATERIAL AND METHODS \\ Cotton cultivation for inoculation}

Plants were grown in $0.5-\mathrm{L}$ plastic pots filled with commercial substrate, made with pine bark, with three plants per pot. Watering was done periodically to maintain water content in the substrate near field capacity. Thirty three cotton genotypes (Table 1) were grown in the greenhouse (minimum and maximum temperatures of 15 and 46 ${ }^{\circ} \mathrm{C}$, respectively) until reaching development stage $\mathrm{V}_{2}$ (MARUR; RUANO, 2001).

Table 1. Brazilian cotton genotypes used to evaluate resistance against S. sclerotiorum.

\begin{tabular}{cccccl}
\hline$\#$ & Genotypes & Institution & $\#$ & Genotypes & Institution \\
\hline 1 & TMG 11 & TMG $^{1}$ & 18 & FM 913 & Fibermax ${ }^{\circledR}-$ Bayer \\
2 & TMG 41 & TMG & 19 & FM 940 & Fibermax ${ }^{\circledR}$ Bayer \\
3 & TMG 42 WS & TMG & 20 & FM 944 GL & Fibermax ${ }^{\circledR}$ - Bayer \\
4 & TMG 43 & TMG & 21 & FM 954 GLT & Fibermax ${ }^{\circledR}$ Bayer \\
5 & TMG 44 B2RF & TMG & 22 & FM 975 WS & Fibermax - Bayer \\
6 & TMG 45 B2RF & TMG & 23 & FM 980 GLT & Fibermax - Bayer \\
7 & TMG 47 B2RF & TMG & 24 & FM 983 GLT & Fibermax ${ }^{\circledR}$ Bayer \\
8 & TMG 48 B2RF & TMG & 25 & IMA 2106 GL & IMA $^{2}$
\end{tabular}




\begin{tabular}{cccccc}
9 & TMG 81 WS & TMG & 26 & IMA 5675 B2RF & IMA \\
10 & TMG 82 WS & TMG & 27 & IMA 8276 WS & IMA \\
11 & BRS 269 & Embrapa & 28 & IMA 8405 GLT & IMA \\
12 & BRS 293 & Embrapa & 29 & DP 1536 B2RF & Deltapine $®$ Monsanto \\
13 & BRS 335 & Embrapa & 30 & DP 1552 & Deltapine ${ }^{\circledR}$ - Monsanto \\
14 & BRS 336 & Embrapa & 31 & IAC 24 & IAC $^{3}$ \\
15 & BRS 368 RF & Embrapa & 32 & IAC 25 & IAC $^{4}$ \\
16 & BRS 369 RF & Embrapa & 33 & MAC-2 & UFU $^{4}$ \\
17 & BRS 371 RF & Embrapa & - & - & - \\
\hline
\end{tabular}

ITMG: Tropical Melhoramento \& Genética; ${ }^{2}$ IMA: Instituto Matogrossense do Algodão; ${ }^{3}$ IAC: Instituto Agronômico de Campinas; ${ }^{4}$ UFU: Cotton Breeding Program at the Universidade Federal de Uberlândia.

\section{Source of fungus strains, inoculation, incubation and evaluations}

Two strains were obtained from sclerotia collected in commercial plantations, one from cotton in the region of Chapadão do Sul (state of Mato Grosso do Sul), and one from soybeans, in the county of Jataí (state of Goiás). Previous study (GARCIA; JULIATTI, 2012) described the soybean strain as highly aggressive. The strains were labeled as $\mathrm{ScC}$ (Sclerotinia sclerotiorum from cotton) and $\mathrm{ScS}$ (the one from soybean).

Sclerotia were previously disinfested with alcohol 50\% $\left(\mathrm{v} \mathrm{v}^{-1}\right)$ for 30 seconds, followed by sodium hypochlorite solution $0.5 \%\left(\mathrm{v} \mathrm{v}^{-1}\right)$ for one minute. Subsequently, they were rinsed three times in sterile distilled water and transferred to Petri dishes containing PDA medium (20\% potato extract, $2 \%$ dextrose, and 2\% agar). The Petri dishes, containing sclerotia, were incubated at $22 \pm 3{ }^{\circ} \mathrm{C}$ and 12 hours lighting for myceliogenic germination. Five-millimeter diameter disks of mycelium were removed from the border of cultures six days after incubation, and used in the tests. Cotton plants, at the phenological stage $V_{2}$, were inoculated with the fungus using the straw test method (PETZOLDT; DICKSON, 1996; CASTRO, 2015). Briefly, cotton apical meristem was bevel cut and a $200-\mu \mathrm{L}$ pippete tip filled with mycelium and PDA disks was placed on top of the stem. The experiment was done with the strains $\mathrm{ScC}$ and $\mathrm{ScS}$ and a negative control, consisting of PDA without the fungus.

Subsequently, plants were incubated in a growth chamber or in the greenhouse for one week. Temperature and lighting in the growth chamber were $22 \pm 3{ }^{\circ} \mathrm{C}$ and 12 hours, respectively; while the environmental conditions (temperature and relative moisture) of the greenhouse were monitored with a digital thermohygrometer. Sclerotinia sclerotiorum lesion extension in the stem was determined with a ruler, seven days post-inoculation (DPI) (PETZOLDT; DICKSON, 1996; SINGH; TERÁN, 2008). The proportion of lesion extension in relation to total stem length (HÜLLER et al., 2016) calculated disease severity.

The experimental design was randomized blocks, with three replications, as a $3 \times 33$ factorial, for both incubation environments. The first factor corresponded to inocula $\mathrm{ScC}, \mathrm{ScS}$ or the control without the pathogen) and the second to cotton genotypes. Each experimental unit consisted of a pot containing three seedlings.

\section{Oxalic acid test}

Seedlings of the 33 cotton genotypes were cut at the root collar, in phenological stage $\mathrm{V}_{2}$, and the shoots were immersed in oxalic acid solutions at 20 or $40 \mathrm{mM}$ (P.A.-A.C.S., Synth). Solution pH was previously adjusted to 4.0 with $10 \mathrm{M}$ sodium hydroxide. Plants were maintained in the solution for 20,44 or 68 hours at $22{ }^{\circ} \mathrm{C}$ in darkness (ANTÔNIO et al., 2008). Three plants of each genotype were evaluated for sensitivity to oxalic acid using a rating scale from 1 (no symptoms) to 5 (completely wilted leaves) (ANTÔNIO et al., 2008).

\section{Statistical analyses}

Data were subjected to the analysis of variance using the factorial strains $x$ genotypes, adopting fixed effects for both factors, followed by Scott-Knott's grouping test at 0.05 significance. The effect of the environment (greenhouse and growth chamber) was evaluated in a grouped comparison by Tukey's test $(p<0.05)$, after the homogeneity of residual variances was confirmed by the proportion between the greatest and the smallest mean square of the residuals (MSR $\leq 7$ ) (RAMALHO et al., 2012). Whenever required, the degrees of freedom were adjusted accordingly.

The genetic parameters of average lesion length and disease severity were estimated from the analysis of variance:

$\mathrm{\theta}_{g}=\frac{M S G-M S R}{r}$ 
$\frac{\hbar^{2}=\sigma_{g}}{\frac{M S G}{r}} \times 100$

where: 圂 $g$ : genetic square component; $h^{2}$ : coefficient of genotypic determination; MSG: mean square of genotypes; MSR: mean square of residuals; and $r$ : number of replications.

$x_{i j}=\frac{x_{i j}}{s\left(X_{i j}\right)}$

The data were standardized by:

where: $x_{i j}$ : standardized average of the $i$-eenth genotype of the j-eenth character; $X_{i j}$ : $i$-eenth genotype of the $j$-eenth character, original data; and $s\left(X_{i j}\right):$ standard deviation.

Genetic dissimilarity was estimated between all genotype pairs by the standardized Euclidian distance, as described:

$$
d_{i v}=\sqrt{\sum_{j}^{p}\left(x_{i j}-x_{i j}\right)^{2}}
$$

where: $\boldsymbol{d}_{i i^{*}}$ : Euclidian distance between genotypes $i$ and $i$; $x_{i j}$ : observation of the $j$-eenth character of genotype $i ; x_{i}{ }^{*}$ : observation for the the $j$-eenth character of genotype $i$; ; and $p$ : number of variables.

Subsequently to obtaining the dissimilarity matrix between the genotypes, these were grouped by the Unweighted Pair Group Method with Arithmetic Mean (UPGMA) and by Tocher's optimization method (RAO, 1952). Both methods were used to increase reliability in the discrimination of genetic divergence of genotypes (NOGUEIRA, 2011; SIMON; KAMADA; MOITEIRO, 2012). A dendrogram was done, using the UPGMA, for the genotypes with greater similarity, and the distance between the genotype and the group formed by individuals $i$ and $j$ was given by:

$$
d_{(i) k}=\frac{d_{i k}+d_{j k}}{2}
$$

Based on Tocher's optimization clustering, the first group consisted of genotypes with the smallest measure of dissimilarity. Subsequently, other genotypes were included in this group, after the comparison between the average distance value within the group and a maximum pre-established value $(\theta)$ of the dissimilarity measure, found in the the group of smallest distances involving each genotype. Inclusion, or not, of each genotype was determined by:

$\frac{d_{(\text {group }) k}}{n} \leq \theta$, genotype $k$ is included in the group;
$\frac{d_{(\text {group }) k}}{n}>\theta$, genotype $k$ is not included; where $n$ is the number of genotypes in the original group.

The distance between genotype $k$ and the group formed by genotypes $i$ and $j$ was given by:

$d_{(i) k}=d_{i k}+d_{j k}$

The average ratings given to the genotypes in the oxalic acid test were submitted to the analysis of variance and grouped by Scott-Knott's test at 0.05 significance. Subsequently, the relation between this variable and lesion length and severity was calculated by Pearson's correlation coefficient (r) for comparison of the two methods to characterized resistance against white mold.

\section{RESULTS}

\section{Resistance of cotton genotypes to infection by $S$. sclerotiorum}

The reaction of cotton genotypes to the pathogen was dependent on the strain inoculated and on plant incubation conditions. The average lesion size caused by the strain $\mathrm{ScS}$, in the growth chamber, was 3.5 fold smaller than that of strain $\mathrm{ScC}$ (4.6 cm long), resulting in lower disease severity (11.9\%) (Table 2). Differences in strain aggressiveness were not significant in the greenhouse: lesion length was restricted to $0.9 \mathrm{~cm}$ for both strains, and disease severity varied from 7.1 to $7.9 \%$ for $\mathrm{ScC}$ and $\mathrm{ScS}$, respectively. Joint analysis of data, considering treatment (combination genotype $\mathrm{x}$ strain) and two environments (growth chamber and greenhouse) detected significant interaction $(\mathrm{P}<0.001)$ between treatment and environment, both for lesion size and disease severity, indicating more favorable infection conditions of cotton seedlings by $S$. sclerotiorum in the growth chamber $(22 \pm 3$ ${ }^{\circ} \mathrm{C}$ and 12 hours lighting), resulting in greater average lesion length and disease severity. In addition, this environment favored greater aggressiveness of the $\mathrm{ScC}$ strain (isolated from cotton).

Table 2. Lesion size $(\mathrm{cm})$ and white mold severity $(\%)$ in cotton genotypes inoculated with S. sclerotiorum. Fungi strains were obtained from soybean $(\mathrm{ScS})$ and cotton $(\mathrm{ScC})$ plants. After inoculation, the genotypes were maintained in a greenhouse or in a growth chamber for seven days. 


\begin{tabular}{cccccc}
\hline \multirow{2}{*}{ Environment } & \multicolumn{2}{c}{ Lesion size $(\mathrm{cm})$} & \multicolumn{2}{c}{ Disease severity (\%) } \\
\cline { 2 - 5 } & $\mathrm{ScS}$ & $\mathrm{ScC}$ & $\mathrm{ScS}$ & $\mathrm{ScC}$ \\
\hline Growth chamber & 1.3 & 4.6 & 11.9 & 41.6 \\
Greenhouse & 0.9 & 0.9 & 7.9 & 7.1 \\
\hline
\end{tabular}

Differences in genotypes response to inoculation, in the greenhouse, varied from 0.5 (genotypes TMG42 WS, IAC25 and TMG47 B2RF) to $1.3 \mathrm{~cm}$ (BRS371 RF and FM954 GLT) for lesion length and from 3.8 (TMG42 WS) to $10.8 \%$ (FM954 GLT) for disease severity (Table 3). Regardless of strain inoculated, genotype FM954 GLT presented the greatest disease severity. In general, values obtained in the greenhouse were smaller than those from the controlled environment. In the growth chamber, lesion length and disease severity reached up to $6 \mathrm{~cm}$ and $66.2 \%$, respectively. The genotypes were grouped into four resistance levels when the plants were inoculated with strain $\mathrm{ScC}$. The most dissimilar groups were formed by the genotypes IMA2106 GL, MAC-2, DP1552 and FM944 GL (considered as resistant to white mold) and the genotypes BRS293, FM975 WS and TMG44 B2RF (susceptible). Sixteen out of the 33 genotypes evaluated had disease severity between 31.7 (TMG43) and 42.1\% (BRS371 RF), while all others (10 genotypes) had severity between 44.4 and $54.7 \%$ (TMG47 B2RF and FM980 GLT, respectively). Among these 10 genotypes, six belong to the same breeding program. No differences were observed among the genotypes after inoculation with strain $\mathrm{ScS}$ (Table 3). The coefficients of genotypic determination $\left(\mathrm{H}^{2}\right)$ were computed for both variables, in both incubation environments. In the greenhouse, $\mathrm{H}^{2}$ was 81.1 and $74.6 \%$ for lesion length and disease severity, respectively, while in the growth chamber, it was $60.2 \%$ for lesion length and $80.8 \%$ for disease severity (Table 3 ).

Genetic diversity among cotton genotypes for resistance to $S$. sclerotiorum by multivariate analyses

Dissimilarity measures obtained by Euclidian distance, based on the 33 genotypes and on the two variables (lesion length and disease severity), for cotton plants inoculated with the strain $\mathrm{ScC}$ are presented in Figure 1. High genetic variability was observed among the genotypes evaluated, with distances in the order between 0.01 and 1.41. It was possible to confirm the greatest similarity between the genotypes IMA8276 WS and IMA8405 GLT $(\mathrm{d}=0.01)$. The comparison between genotypes FM944 GL and FM975 WS was the most divergent $(\mathrm{d}=1.41)$. Among the estimates of genetic divergence, the genotype FM944 GL was presented in the most distant comparisons, indicating little similarity with all others. The matrix data were used to make a dendrogram according to the method of average linkage between groups (UPGMA) (Figure 2 ). The coefficient of cophenetic correlation obtained was 0.8012 , significant at $1 \%$ probability by the $t$ test. The genotypes were discriminated into five groups, considering $33 \%$ dissimilarity as delimitation. The first group consisted of 20 genotypes, i.e., $60.6 \%$ of the observed genetic diversity, followed by group II containing nine genotypes. Groups III (genotypes BRS293 and FM975 WS) and IV (TMG44 B2RF) contained the most susceptible materials, according to the straw test. The fifth group was represented by genotype FM944 GL, considered resistant in the inoculation test. The dendrogram reiterates the great genetic divergence between this material and all others.

The same matrix of Euclidian distance was used to group the genotypes by Tocher's optimization method. This method resulted in four groups (Table 4), one less than that of UPGMA method. The genotype TMG44 B2RF, previously separated into an exclusive group by UPGMA, was grouped with BRS293 and FM975 WS (previously in group III). In Tocher's clustering, group I consisted of 25 genotypes (75.8\% of the total), group II of four genotypes (TMG43, IMA2106 GL, MAC-2 and TMG47 B2RF) and group III of genotypes BRS293, FM975 WS and TMG44 B2RF. Groups III and IV, obtained by Tocher's optimization method, corresponded, respectively, to the materials considered as most susceptible and most resistant by the straw test. 
Table 3. Resistance of Brazilian cotton genotypes to strains of S. sclerotiorum determined after incubation of the plants in the greenhouse and in the growth chamber.

\begin{tabular}{|c|c|c|c|c|c|c|c|c|}
\hline \multirow{3}{*}{ Genotype } & \multicolumn{2}{|c|}{ Lesion length $(\mathrm{cm})$} & \multicolumn{2}{|c|}{ Severity $(\%)$} & \multicolumn{2}{|c|}{ Lesion length $(\mathrm{cm})$} & \multicolumn{2}{|c|}{ Severity (\%) } \\
\hline & $\mathrm{ScS}$ & $\mathrm{ScC}$ & $\mathrm{ScS}$ & $\mathrm{ScC}$ & $\mathrm{ScS}$ & $\mathrm{ScC}$ & $\mathrm{ScS}$ & $\mathrm{ScC}$ \\
\hline & \multicolumn{4}{|c|}{ Greenhouse } & \multicolumn{4}{|c|}{ Growth chamber } \\
\hline TMG42 WS & $0.7 \mathrm{~b} \mathrm{~A}^{1^{+}}$ & $0.5 \mathrm{~b} \mathrm{~A}^{+}$ & $5.7 \mathrm{~b} \mathrm{~A}^{*}$ & $3.8 \mathrm{~b} \mathrm{~A}^{*}$ & $1.9 \mathrm{a} \mathrm{B}^{+}$ & $4.5 \mathrm{a} \mathrm{A}^{+}$ & $17.0 \mathrm{a} \mathrm{B}^{*}$ & $47.4 \mathrm{~b} \mathrm{~A}^{*}$ \\
\hline IAC25 & $0.7 \mathrm{~b} \mathrm{~A}$ & $0.5 \mathrm{~b} \mathrm{~A}^{+}$ & $6.3 \mathrm{~b} \mathrm{~A}$ & $4.2 \mathrm{~b} \mathrm{~A}^{*}$ & 0.9 a B & $4.6 \mathrm{a} \mathrm{A}^{+}$ & 8.2 a B & $32.5 \mathrm{c} \mathrm{A}^{*}$ \\
\hline IMA5675 B2RF & $0.8 \mathrm{~b} \mathrm{~A}^{+}$ & $0.7 \mathrm{~b} \mathrm{~A}^{+}$ & $6.0 \mathrm{~b} \mathrm{~A}^{*}$ & $4.5 \mathrm{~b} \mathrm{~A}^{*}$ & $2.7 \mathrm{a} \mathrm{B}^{+}$ & $4.8 \mathrm{a} \mathrm{A}^{+}$ & $22.4 \mathrm{a} \mathrm{A}^{*}$ & $34.4 \mathrm{c} \mathrm{A}^{*}$ \\
\hline TMG47 B2RF & $0.8 \mathrm{~b} \mathrm{~A}$ & $0.5 \mathrm{~b} \mathrm{~A}^{+}$ & $8.1 \mathrm{a} \mathrm{A}$ & $4.6 \mathrm{~b} \mathrm{~A}^{*}$ & $1.4 \mathrm{a} \mathrm{B}$ & $3.6 \mathrm{~b} \mathrm{~A}^{+}$ & 14.7 a B & $44.4 \mathrm{~b} \mathrm{~A}^{*}$ \\
\hline IMA8276 WS & $1.1 \mathrm{a} \mathrm{A}$ & $0.8 \mathrm{~b} \mathrm{~A}^{+}$ & $7.1 \mathrm{~b} \mathrm{~A}$ & $4.6 \mathrm{~b} \mathrm{~A}^{*}$ & 0.8 a B & $5.7 \mathrm{a} \mathrm{A}^{+}$ & 5.8 a B & $39.2 \mathrm{c} \mathrm{A}^{*}$ \\
\hline TMG43 & $0.7 \mathrm{~b} \mathrm{~A}^{+}$ & $0.6 \mathrm{~b} \mathrm{~A}^{+}$ & $5.9 \mathrm{~b} \mathrm{~A}$ & $5.0 \mathrm{~b} \mathrm{~A}^{*}$ & $1.7 \mathrm{a} \mathrm{B}^{+}$ & $3.8 \mathrm{~b} \mathrm{~A}^{+}$ & 15.5 a B & 31.7 c A $^{*}$ \\
\hline TMG11 & $0.8 \mathrm{~b} \mathrm{~A}$ & $0.7 \mathrm{~b} \mathrm{~A}^{+}$ & $7.0 \mathrm{~b} \mathrm{~A}$ & $5.6 \mathrm{~b} \mathrm{~A}^{*}$ & $1.5 \mathrm{a} \mathrm{B}$ & $4.1 \mathrm{~b} \mathrm{~A}^{+}$ & $12.1 \mathrm{a} \mathrm{B}$ & $39.4 \mathrm{c} \mathrm{A}^{*}$ \\
\hline TMG41 & $1.1 \mathrm{a} \mathrm{A}$ & $0.7 \mathrm{~b} \mathrm{~A}^{+}$ & $9.1 \mathrm{a} \mathrm{A}$ & $5.8 \mathrm{~b} \mathrm{~A}^{*}$ & $1.5 \mathrm{a} \mathrm{B}$ & $4.2 \mathrm{~b} \mathrm{~A}^{+}$ & $13.3 \mathrm{a} \mathrm{B}$ & $41.4 \mathrm{c} \mathrm{A}^{*}$ \\
\hline IAC24 & $0.6 \mathrm{~b} \mathrm{~A}$ & $0.7 \mathrm{~b} \mathrm{~A}^{+}$ & $5.2 \mathrm{~b} \mathrm{~A}$ & $5.9 \mathrm{~b} \mathrm{~A}^{*}$ & $1.5 \mathrm{a} \mathrm{B}$ & $5.0 \mathrm{a} \mathrm{A}^{+}$ & 12.8 a B & $48.0 \mathrm{~b} \mathrm{~A}^{*}$ \\
\hline BRS336 & $0.7 \mathrm{~b} \mathrm{~A}$ & $0.7 \mathrm{~b} \mathrm{~A}^{+}$ & $5.8 \mathrm{~b} \mathrm{~A}$ & $6.2 \mathrm{~b} \mathrm{~A}^{*}$ & 0.9 a B & $4.7 \mathrm{a} \mathrm{A}^{+}$ & 8.5 a B & 38.9 c A $^{*}$ \\
\hline FM983 GLT & $1.0 \mathrm{a} \mathrm{A}$ & $0.8 \mathrm{~b} \mathrm{~A}^{+}$ & 8.6 a A & $6.4 \mathrm{~b} \mathrm{~A}^{*}$ & $2.1 \mathrm{a} \mathrm{B}$ & $4.6 \mathrm{a} \mathrm{A}^{+}$ & $17.1 \mathrm{a} \mathrm{B}$ & $35.3 \mathrm{c} \mathrm{A}^{*}$ \\
\hline FM980 GLT & $1.0 \mathrm{a} \mathrm{A}$ & $0.7 \mathrm{~b} \mathrm{~A}^{+}$ & $9.4 \mathrm{a} \mathrm{A}$ & $6.5 \mathrm{~b} \mathrm{~A}^{*}$ & $1.3 \mathrm{a} \mathrm{B}$ & $5.1 \mathrm{a} \mathrm{A}^{+}$ & 16.6 a B & 54.7 b A $^{*}$ \\
\hline FM913 & $1.0 \mathrm{a} \mathrm{A}$ & $0.7 \mathrm{~b} \mathrm{~A}^{+}$ & 8.7 a A & $6.9 \mathrm{a} \mathrm{A}^{*}$ & $1.4 \mathrm{a} \mathrm{B}$ & $4.8 \mathrm{a} \mathrm{A}^{+}$ & 10.8 a B & $41.1 \mathrm{c} \mathrm{A}^{*}$ \\
\hline IMA8405 GLT & $0.9 \mathrm{~b} \mathrm{~A}$ & $0.8 \mathrm{~b} \mathrm{~A}^{+}$ & $7.7 \mathrm{~b} \mathrm{~A}$ & $6.9 \mathrm{a} \mathrm{A}^{*}$ & $1.2 \mathrm{a} \mathrm{B}$ & $5.7 \mathrm{a} \mathrm{A}^{+}$ & 10.0 a B & $39.0 \mathrm{c} \mathrm{A}^{*}$ \\
\hline BRS269 & $1.0 \mathrm{a} \mathrm{A}$ & $0.9 \mathrm{~b} \mathrm{~A}^{+}$ & 8.7 a A & $7.1 \mathrm{a} \mathrm{A}^{*}$ & $1.3 \mathrm{a} \mathrm{B}$ & $3.8 \mathrm{~b} \mathrm{~A}^{+}$ & $15.1 \mathrm{a} \mathrm{B}$ & $34.6 \mathrm{c} \mathrm{A}^{*}$ \\
\hline TMG82 WS & $0.7 \mathrm{~b} \mathrm{~A}$ & $0.9 \mathrm{~b} \mathrm{~A}^{+}$ & $5.6 \mathrm{~b} \mathrm{~A}$ & $7.2 \mathrm{a} \mathrm{A}^{*}$ & 1.7 a B & $4.7 \mathrm{a} \mathrm{A}^{+}$ & 14.9 a B & $47.3 \mathrm{~b} \mathrm{~A}^{*}$ \\
\hline IMA2106 GL & $1.0 \mathrm{a} \mathrm{A}$ & $1.0 \mathrm{a} \mathrm{A}^{+}$ & $8.3 \mathrm{a} \mathrm{A}$ & $7.3 \mathrm{a} \mathrm{A}^{*}$ & $1.1 \mathrm{a} \mathrm{B}$ & $3.8 \mathrm{~b} \mathrm{~A}^{+}$ & 9.0 a B & $24.1 \mathrm{~d} \mathrm{~A}^{*}$ \\
\hline MAC-2 & $0.8 \mathrm{~b} \mathrm{~A}$ & $0.7 \mathrm{~b} \mathrm{~A}^{+}$ & 7.9 a A & $7.3 \mathrm{a} \mathrm{A}^{*}$ & $1.2 \mathrm{a} \mathrm{B}$ & $3.1 \mathrm{~b} \mathrm{~A}^{+}$ & 9.5 a B & $25.6 \mathrm{~d} \mathrm{~A}^{*}$ \\
\hline BRS335 & $0.8 \mathrm{~b} \mathrm{~A}$ & $0.9 \mathrm{~b} \mathrm{~A}^{+}$ & $6.6 \mathrm{~b} \mathrm{~A}$ & 7.5 a $\mathrm{A}^{*}$ & 0.5 a B & $5.4 \mathrm{a} \mathrm{A}^{+}$ & 4.3 a B & $51.6 \mathrm{~b} \mathrm{~A}^{*}$ \\
\hline BRS293 & $1.1 \mathrm{a} \mathrm{A}$ & $1.0 \mathrm{a} \mathrm{A}^{+}$ & 8.2 a A & $7.7 \mathrm{a} \mathrm{A}^{*}$ & $1.1 \mathrm{a} \mathrm{B}$ & $5.5 \mathrm{a} \mathrm{A}^{+}$ & 12.8 a B & $64.6 \mathrm{a} \mathrm{A}^{*}$ \\
\hline BRS369 RF & $1.2 \mathrm{a} \mathrm{A}$ & $1.2 \mathrm{a} \mathrm{A}^{+}$ & 8.8 a A & 7.7 a $A^{*}$ & $1.0 \mathrm{a} \mathrm{B}$ & $5.4 \mathrm{a} \mathrm{A}^{+}$ & 7.8 a B & $41.2 \mathrm{c} \mathrm{A}^{*}$ \\
\hline TMG45 B2RF & $0.7 \mathrm{~b} \mathrm{~A}$ & $0.7 \mathrm{~b} \mathrm{~A}^{+}$ & $7.6 \mathrm{~b} \mathrm{~A}$ & $7.8 \mathrm{a} \mathrm{A}^{*}$ & $1.1 \mathrm{a} \mathrm{B}$ & $4.4 \mathrm{a} \mathrm{A}^{+}$ & $13.1 \mathrm{a} \mathrm{B}$ & $46.2 \mathrm{~b} \mathrm{~A}^{*}$ \\
\hline DP1552 & $1.2 \mathrm{a} \mathrm{A}^{+}$ & $1.0 \mathrm{a} \mathrm{A}^{+}$ & 8.9 a A & $7.8 \mathrm{a} \mathrm{A}^{*}$ & $2.3 \mathrm{a} \mathrm{B}^{+}$ & $4.8 \mathrm{a} \mathrm{A}^{+}$ & $17.6 \mathrm{a} \mathrm{A}$ & $26.8 \mathrm{~d} \mathrm{~A}^{*}$ \\
\hline TMG81 WS & $0.7 \mathrm{~b} \mathrm{~A}$ & $0.8 \mathrm{~b} \mathrm{~A}^{+}$ & $7.1 \mathrm{~b} \mathrm{~A}$ & $7.9 \mathrm{a} \mathrm{A}^{*}$ & $1.3 \mathrm{a} \mathrm{B}$ & $4.7 \mathrm{a} \mathrm{A}^{+}$ & $11.3 \mathrm{a} \mathrm{B}$ & $50.1 \mathrm{~b} \mathrm{~A}^{*}$ \\
\hline BRS368 RF & $1.1 \mathrm{a} \mathrm{A}$ & $1.2 \mathrm{a} \mathrm{A}^{+}$ & $7.6 \mathrm{~b} \mathrm{~A}$ & $8.0 \mathrm{a} \mathrm{A}^{*}$ & $1.2 \mathrm{a} \mathrm{B}$ & $5.0 \mathrm{a} \mathrm{A}^{+}$ & $9.1 \mathrm{a} \mathrm{B}$ & 36.6. $\mathrm{c} \mathrm{A}^{*}$ \\
\hline FM944 GL & $1.0 \mathrm{a} \mathrm{A}$ & $0.9 \mathrm{~b} \mathrm{~A}^{+}$ & 9.6 a A & $8.5 \mathrm{a} \mathrm{A}^{*}$ & $1.0 \mathrm{a} \mathrm{A}$ & $2.3 \mathrm{~b} \mathrm{~A}^{+}$ & $6.3 \mathrm{a} A$ & $12.0 \mathrm{~d} \mathrm{~A}^{*}$ \\
\hline
\end{tabular}




\begin{tabular}{|c|c|c|c|c|c|c|c|c|}
\hline FM940 & $0.7 \mathrm{~b} \mathrm{~A}$ & $0.9 \mathrm{a} \mathrm{A}^{+}$ & $6.8 \mathrm{~b} \mathrm{~A}$ & $8.7 \mathrm{a} \mathrm{A}^{*}$ & 0.7 a B & $5.3 \mathrm{a} \mathrm{A}^{+}$ & 6.5 a B & $50.4 \mathrm{~b} \mathrm{~A}^{*}$ \\
\hline TMG48 B2RF & $1.2 \mathrm{a} \mathrm{A}$ & $1.0 \mathrm{a} \mathrm{A}^{+}$ & 10.4 a A & $8.7 \mathrm{a} \mathrm{A}^{*}$ & $1.3 \mathrm{a} \mathrm{B}$ & $4.9 \mathrm{a} \mathrm{A}^{+}$ & $13.2 \mathrm{a} \mathrm{B}$ & $48.6 \mathrm{~b} \mathrm{~A}^{*}$ \\
\hline FM975 WS & $1.1 \mathrm{a} \mathrm{A}$ & $1.2 \mathrm{a} \mathrm{A}^{+}$ & 8.4 a A & $9.1 \mathrm{a} \mathrm{A}^{*}$ & $1.6 \mathrm{a} \mathrm{B}$ & $6.0 \mathrm{a} \mathrm{A}^{+}$ & 17.4 a B & $66.2 \mathrm{a} \mathrm{A}^{*}$ \\
\hline BRS371 RF & $1.2 \mathrm{a} \mathrm{A}$ & $1.3 \mathrm{a} \mathrm{A}^{+}$ & 9.0 a A & $9.2 \mathrm{a} \mathrm{A}^{*}$ & $1.6 \mathrm{a} \mathrm{B}$ & $4.9 \mathrm{a} \mathrm{A}^{+}$ & $11.5 \mathrm{a} \mathrm{B}$ & $42.1 \mathrm{c} \mathrm{A}^{*}$ \\
\hline TMG44 B2RF & $1.0 \mathrm{a} A$ & $0.7 \mathrm{~b} \mathrm{~A}^{+}$ & 10.7 a A & $9.7 \mathrm{a} \mathrm{A}^{*}$ & $1.3 \mathrm{a} \mathrm{B}$ & $4.7 \mathrm{a} \mathrm{A}^{+}$ & $13.4 \mathrm{a} \mathrm{B}$ & $64.8 \mathrm{a} \mathrm{A}^{*}$ \\
\hline DP1536 B2RF & $1.0 \mathrm{a} A$ & $1.2 \mathrm{a} \mathrm{A}^{+}$ & 7.9 a A & $9.8 \mathrm{a} \mathrm{A}^{*}$ & 0.9 a B & $4.9 \mathrm{a} \mathrm{A}^{+}$ & 6.5 a B & $38.7 \mathrm{c} \mathrm{A}^{*}$ \\
\hline FM954 GLT & $1.3 \mathrm{a} \mathrm{A}$ & $1.2 \mathrm{a} \mathrm{A}^{+}$ & 10.8 a A & $10.4 \mathrm{a} \mathrm{A}^{*}$ & $1.1 \mathrm{a} \mathrm{B}$ & $3.9 \mathrm{~b} \mathrm{~A}^{+}$ & $10.2 \mathrm{a} \mathrm{B}$ & $34.1 \mathrm{c} \mathrm{A}^{*}$ \\
\hline Average & 0.9 & 0.9 & 7.9 & 7.1 & 1.3 & 4.6 & 11.9 & 41.6 \\
\hline $\mathrm{CV}(\%)$ & \multicolumn{2}{|c|}{22.75} & \multicolumn{2}{|c|}{23.73} & \multicolumn{2}{|c|}{22.94} & \multicolumn{2}{|c|}{26.41} \\
\hline $\mathrm{H}^{2}(\%)$ & \multicolumn{2}{|c|}{81.11} & \multicolumn{2}{|c|}{74.64} & \multicolumn{2}{|c|}{60.18} & \multicolumn{2}{|c|}{80.79} \\
\hline
\end{tabular}

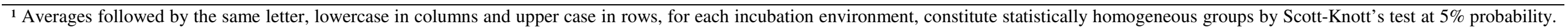

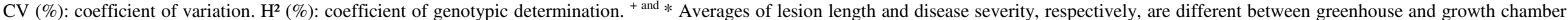
by Tukey's test at 0.05 significance, considering MSR of the joint analysis. 


\begin{tabular}{|c|c|c|c|c|c|c|c|c|c|c|c|c|c|c|c|c|c|c|c|c|c|c|c|c|c|c|c|c|c|c|c|c|}
\hline & TMG & TMG & TMG & TMG & TMG & TMG & TMG & TMG & TMG & BRS & BRS & BRS & BRS & BRS & BRS & BRS $\mathrm{F}$ & FM 913 F & FM $940 \mathrm{~F}$ & $\overline{\mathrm{FM}} 944 \mathrm{Fl}$ & FM 954 F & PM $975 \mathrm{~F}$ & FM $980 \mathrm{~F}$ & FM 983 & IMA & IMA & IMA & IMA & DP & DP & IAC 24 I & $\mathrm{IAC} 25$ & $\overline{\mathrm{MAC}-2}$ \\
\hline Genótipos & 41 & $42 \mathrm{WS}$ & 43 & $\begin{array}{c}44 \\
\text { B2RF }\end{array}$ & $\begin{array}{c}45 \\
\text { B2RF }\end{array}$ & $\begin{array}{c}47 \\
\text { B2RF }\end{array}$ & $\begin{array}{c}48 \\
\text { B2RF }\end{array}$ & $81 \mathrm{WS}$ & $82 \mathrm{WS}$ & 269 & 293 & 335 & 336 & $368 \mathrm{RF} 3$ & $369 \mathrm{RF} 3$ & $371 \mathrm{RF}$ & & & GL & GLT & WS & GLT & GLT 2 & $2106 \mathrm{GL}$ & $\begin{array}{l}5675 \\
\text { B2RF }\end{array}$ & $\begin{array}{l}8276 \\
\text { WS }\end{array}$ & $\begin{array}{l}8405 \\
\text { GLT }\end{array}$ & $\begin{array}{c}1536 \\
\text { B2RF }\end{array}$ & 1552 & & & \\
\hline TMG 11 & 0,045 & 0,187 & 0,168 & 0,491 & 0,140 & 0,170 & 0,263 & 0,256 & 0,207 & 0,123 & 0,590 & 0,415 & 0,150 & 0,256 & 0,357 & 0,209 & 0,197 & 0,385 & 0,705 & 0,117 & 0,709 & 0,385 & 0,160 & 0,298 & 0,213 & 0,426 & 0,417 & 0,204 & 0,300 & 0,298 & 0,185 & $\overline{0,373}$ \\
\hline TMG 41 & & 0,142 & 0,213 & 0,448 & 0,096 & 0,175 & 0,220 & 0,211 & 0,164 & 0,167 & 0,545 & 0,375 & 0,134 & 0,244 & 0,331 & 0,179 & 0,171 & 0,345 & 0,750 & 0,162 & 0,665 & 0,341 & 0,162 & 0,342 & 0,212 & 0,404 & 0,395 & 0,187 & 0,317 & 0,258 & 0,198 & 0,417 \\
\hline TMG 42 WS & & & 0,355 & 0,323 & 0,056 & 0,263 & 0,089 & 0,069 & 0,032 & 0,310 & 0,403 & 0,246 & 0,161 & 0,241 & 0,266 & 0,131 & 0,141 & 0,219 & 0,892 & 0,303 & 0,524 & 0,199 & 0,225 & 0,479 & 0,252 & 0,346 & 0,340 & 0,184 & 0,387 & 0,138 & 0,275 & 0,559 \\
\hline TMG 43 & & & & 0,654 & 0,308 & 0,240 & 0,426 & 0,423 & 0,373 & 0,054 & 0,757 & 0,572 & 0,274 & 0,353 & 0,478 & 0,350 & 0,334 & 0,541 & 0,542 & 0,052 & 0,873 & 0,551 & 0,240 & 0,141 & 0,287 & 0,535 & 0,525 & 0,321 & 0,295 & 0,456 & 0,226 & 0,214 \\
\hline TMG 44 B2RF & & & & & 0,353 & 0,473 & 0,305 & 0,273 & 0,323 & 0,603 & 0,218 & 0,318 & 0,479 & 0,531 & 0,484 & 0,423 & 0,440 & 0,322 & 1,164 & 0,604 & 0,364 & 0,220 & 0,544 & 0,789 & 0,563 & 0,550 & , 548 & 0,486 & 0,702 & 0,328 & 0,596 & 0,836 \\
\hline TMG 45 B2RF & & & & & & 0,208 & 0,144 & 0,123 & 0,086 & 0,260 & 0,453 & 0,302 & 0,160 & 0,257 & 0,306 & 0,158 & 0,161 & 0,274 & 0,840 & 0,256 & 0,578 & 0,253 & 0,215 & 0,438 & 0,252 & 0,385 & 0,377 & 0,197 & 0,379 & 0,192 & 0,262 & 0,507 \\
\hline TMG $47 \mathrm{~B} 2 \mathrm{RF}$ & & & & & & & 0,351 & 0,322 & 0,294 & 0,189 & 0,627 & 0,508 & 0,309 & 0,418 & 0,501 & 0,347 & 0,342 & 0,481 & 0,693 & 0,206 & 0,764 & 0,446 & 0,329 & 0,378 & 0,382 & 0,576 & 0,568 & 0,362 & 0,465 & 400 & 0,353 & 0,371 \\
\hline TMG 48 B2RF & & & & & & & & 0,047 & 0,059 & 0,385 & 0,337 & 0,158 & 0,186 & 0,226 & 0,206 & 0,119 & 0,138 & 0,130 & 0,967 & 0,376 & 0,448 & 0,129 & 0,252 & 0,540 & 0,261 & 0,284 & 0,279 & 0,182 & 0,401 & 0,052 & 0,303 & 0,635 \\
\hline TMG 81 WS & & & & & & & & & 0,053 & 0,378 & 0,334 & 0,188 & 0,207 & 0,263 & 0,253 & 0,152 & 0,168 & 0,163 & 0,961 & 0,372 & 0,456 & 0,130 & 0,273 & 0,545 & 0,290 & 0,331 & , 326 & 0,214 & 0,430 & 0,097 & ,325 & 0,628 \\
\hline TMG 82 WS & & & & & & & & & & 0,330 & 0,385 & 0,217 & 0,156 & 0,224 & 0,238 & 0,111 & 0,125 & 0,189 & 0,913 & 0,322 & 0,502 & 0,178 & 0,222 & 0,493 & 0,243 & 0,317 & 0,311 & 0,170 & 0,381 & 0,106 & 0,273 & 0,580 \\
\hline BRS 269 & & & & & & & & & & & 0,712 & 0,536 & 0,248 & 0,339 & 0,457 & 0,320 & 0,305 & 0,505 & 0,582 & 0,025 & 0,832 & 0,508 & 0,227 & 0,195 & 0,278 & 0,519 & 0,510 & 0,300 & 0,312 & 0,419 & 224 & 0,250 \\
\hline BRS 293 & & & & & & & & & & & & 0,241 & 0,520 & 0,528 & 0,432 & 0,445 & 0,465 & 0,264 & 1,293 & 0,706 & 0,148 & 0,209 & 0,584 & 0,877 & 0,583 & 0,473 & 475 & 0,504 & 0,718 & 0,326 & 0,634 & 0,960 \\
\hline BRS 335 & & & & & & & & & & & & & 0,308 & 0,293 & 0,192 & 0,228 & 0,247 & 0,031 & 1,114 & 0,523 & 0,314 & 0,105 & 0,365 & 0,674 & 0,353 & 0,241 & 0,241 & 0,279 & 0,483 & 0,117 & 0,411 & 0,785 \\
\hline BRS 336 & & & & & & & & & & & & & & 0,109 & 0,210 & 0,080 & 0,061 & 0,277 & 0,811 & 0,230 & 0,619 & 0,313 & 0,066 & 0,367 & 0,093 & 0,277 & 0,267 & 0,055 & 0,226 & 0,197 & 0,118 & 0,488 \\
\hline BRS 368 RF & & & & & & & & & & & & & & & 0,134 & 0,112 & 0,100 & 0,266 & 0,871 & 0,318 & 0,604 & 0,334 & 0,113 & 0,416 & 0,072 & 0,182 & 0,172 & 0,060 & 0,190 & 0,210 & 0,139 & 0,561 \\
\hline BRS $369 \mathrm{RF}$ & & & & & & & & & & & & & & & & 0,154 & 0,160 & 0,173 & 1,004 & 0,438 & 0,487 & 0,267 & 0,240 & 0,550 & 0,205 & 0,080 & 0,074 & 0,158 & 0,312 & 0,163 & 0,272 & 0,690 \\
\hline BRS 371 RF & & & & & & & & & & & & & & & & & 0,020 & 0,197 & 0,890 & 0,304 & 0,539 & 0,240 & 0,140 & 0,447 & 0,143 & 0,230 & 0,222 & 0,064 & 0,282 & 0,119 & 0,189 & 0,564 \\
\hline FM 913 & & & & & & & & & & & & & & & & & & 0,216 & 0,872 & 0,289 & 0,559 & 0,260 & 0,120 & 0,428 & 0,124 & 0,234 & 0,225 & 0,046 & 0,264 & 0,139 & 0,170 & 0,548 \\
\hline FM 940 & & & & & & & & & & & & & & & & & & & 1,083 & 0,493 & 0,343 & 0,102 & 0,335 & 0,643 & 0,325 & 0,230 & 0,229 & 0,249 & 0,456 & 887 & 0,382 & 0,754 \\
\hline FM $944 \mathrm{GL}$ & & & & & & & & & & & & & & & & & & & & 0,592 & 1,414 & 1,090 & 0,765 & 0,455 & 0,799 & 1,046 & 1,037 & 0,853 & 0,735 & 998 & 0,732 & 0,333 \\
\hline FM 954 GLT & & & & & & & & & & & & & & & & & & & & & 0,823 & 0,500 & 0,205 & 0,188 & 0,255 & 0,498 & 0,489 & 0,280 & 0,287 & 0,407 & 0,200 & 0,261 \\
\hline FM 975 WS & & & & & & & & & & & & & & & & & & & & & & 0,325 & 0,678 & 0,984 & 0,667 & 0,505 & 0,510 & 0,592 & 0,793 & 0,422 & 0,725 & 1,082 \\
\hline FM $980 \mathrm{GLT}$ & & & & & & & & & & & & & & & & & & & & & & & 0,378 & 0,668 & 0,381 & 0,330 & 0,329 & 0,301 & 0,519 & 0,124 & 0,428 & 0,757 \\
\hline FM $983 \mathrm{G}$ & & & & & & & & & & & & & & & & & & & & & & & & 0,314 & 0,054 & 0,294 & 0,285 & 0,089 & 0,164 & 0,259 & 0,052 & 0,450 \\
\hline IMA $2106 \mathrm{GL}$ & & & & & & & & & & & & & & & & & & & & & & & & & 0,345 & 0,591 & 0,582 & 0,403 & 0,290 & 0,562 & 0,278 & 0,179 \\
\hline IMA 5675 B2RF & & & & & & & & & & & & & & & & & & & & & & & & & & 0,250 & 0,241 & 0,080 & 0,140 & 0,258 & 0,067 & 0,492 \\
\hline IMA 8276 WS & & & & & & & & & & & & & & & & & & & & & & & & & & & 0,010 & 0,222 & 0,328 & 0,238 & 0,316 & 0,742 \\
\hline IMA 8405 GLT & & & & & & & & & & & & & & & & & & & & & & & & & & & & 0,213 & 0,319 & 0,234 & 0,307 & 0,732 \\
\hline DP 15 & & & & & & & & & & & & & & & & & & & & & & & & & & & & & 0,219 & 0,17 & 0,133 & 0,53 \\
\hline DP 1552 & & & & & & & & & & & & & & & & & & & & & & & & & & & & & & 0,395 & 0,119 & 0,463 \\
\hline IAC 24 & & & & & & & & & & & & & & & & & & & & & & & & & & & & & & & 0,309 & 668 \\
\hline IAC 25 & & & & & & & & & & & & & & & & & & & & & & & & & & & & & & & & 42 \\
\hline
\end{tabular}

Figure 1. Dissimilarity, based on Euclidian distance, between 33 Brazilian cotton genotypes as a function of lesion length and disease severity of white mold. Plants were inoculated with strain $\mathrm{ScC}$ (S. sclerotiorum isolated from cotton plants) and incubated in a growth chamber. 


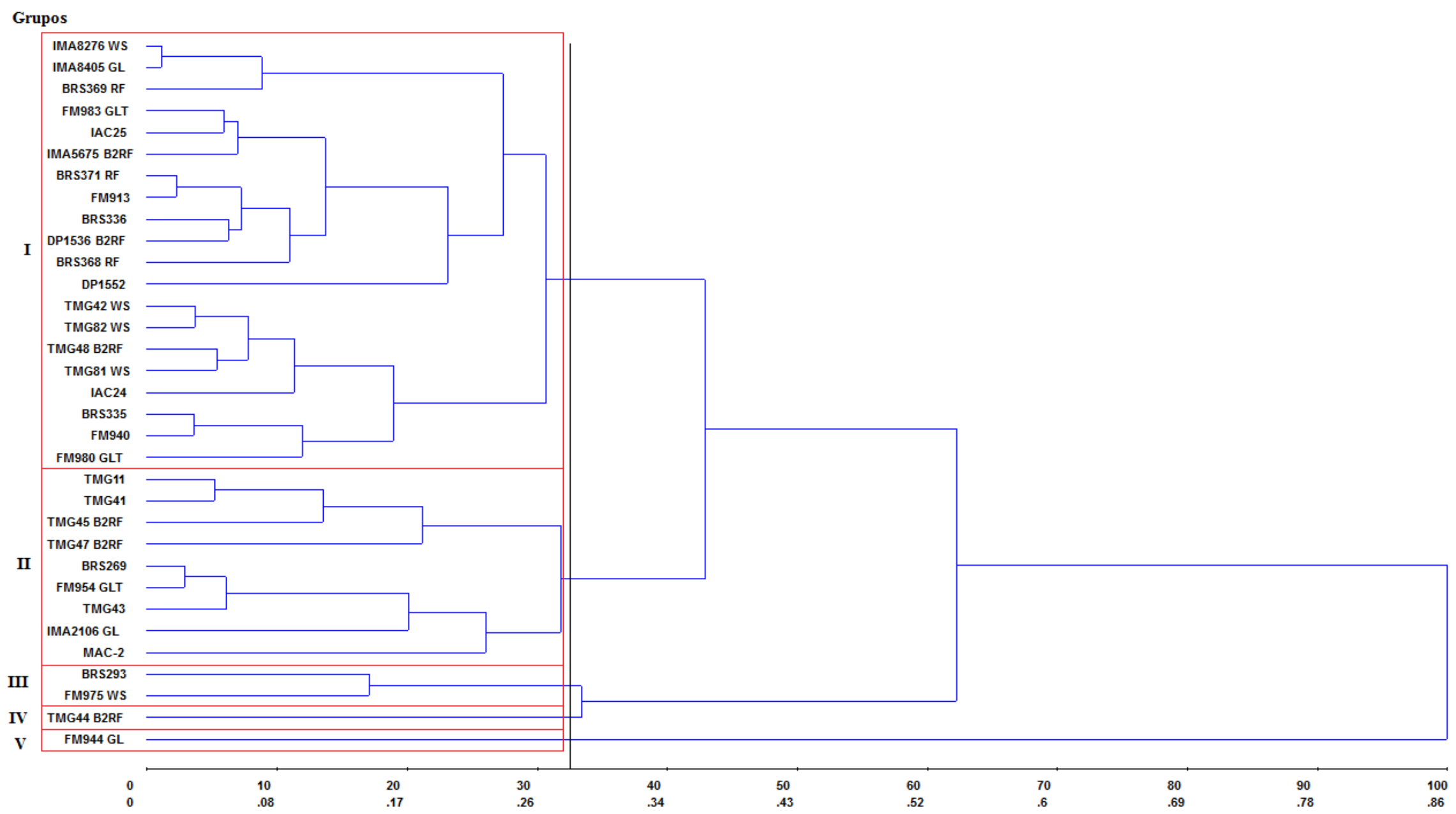

Figure 2. Dendrogram representative of genetic dissimilarity between 33 cotton genotypes by the average linkage between group (UPGMA) hierarchical clustering. Diagram obtained by Euclidian distance as a function of lesion size and white mold severity evaluated seven days after plant inoculation with $\mathrm{S}$. sclerotiorum strain $\mathrm{ScC}$. For symptoms development, the plants were incubated in a growth chamber (temperature $22 \pm 3{ }^{\circ} \mathrm{C}$ and 12 hours photoperiod). Coefficient of cophenetic correlation $(r)=0.8012 * *$. ** Significant at $1 \%$ probability by t-test. 
Table 4. Grouping of 33 cotton genotypes by Tocher's optimization method. The groups were obtained by Euclidian distance as a function of lesion length and disease severity of white mold, after inoculation of plants with the strain ScC of S. sclerotiorum. Plants were incubated for one week in a growth chamber $\left(22 \pm 3{ }^{\circ} \mathrm{C}\right.$ and 12 hours lighting) for symptoms development.

\begin{tabular}{cc}
\hline Group & Genotypes \\
\hline & IMA8276 WS, IMA8405 GLT, BRS369 RF, BRS368 RF, DP1536B2 RF, FM913 BRS371 RF, \\
I & BRS336, IMA5675 B2RF, FM983 GLT, IAC25, IAC24, TMG48 B2RF TMG82 WS, TMG42 WS, \\
& TMG81 WS, TMG45 B2RF, TMG41, TMG11, FM940 BRS335, FM980 GLT, DP1552, FM954 \\
II & GLT and BRS269 \\
III & TMG43, IMA2106 GL, MAC-2 and TMG47 B2RF \\
IV & BRS293, FM975 WS and TMG44 B2RF \\
\hline
\end{tabular}

Evaluation of cotton genotypes resistance to $S$. sclerotiorum by the oxalic acid test

A score scale (varying from 1 to 5) estimated indirect evaluation of cotton genotypes resistance with smaller values to genotypes less sensitive to oxalic acid solution (Table 5). Exposure time and solution concentration were relevant to genotype discrimination. Greater scores were obtained at the concentration of $40 \mathrm{mM}$ for 68 hours, except for genotypes BRS269, DP1552 and TMG43, which had greater score at $20 \mathrm{mM}$ for 44 hours.

Table 5. Wilting scores of Brazilian cotton genotypes ( 1 - no symptoms, to 5 - completely wilted leaves) as a function of oxalic acid concentration $(\mathrm{mM})$ and exposure time (h) of seedlings to the solution.

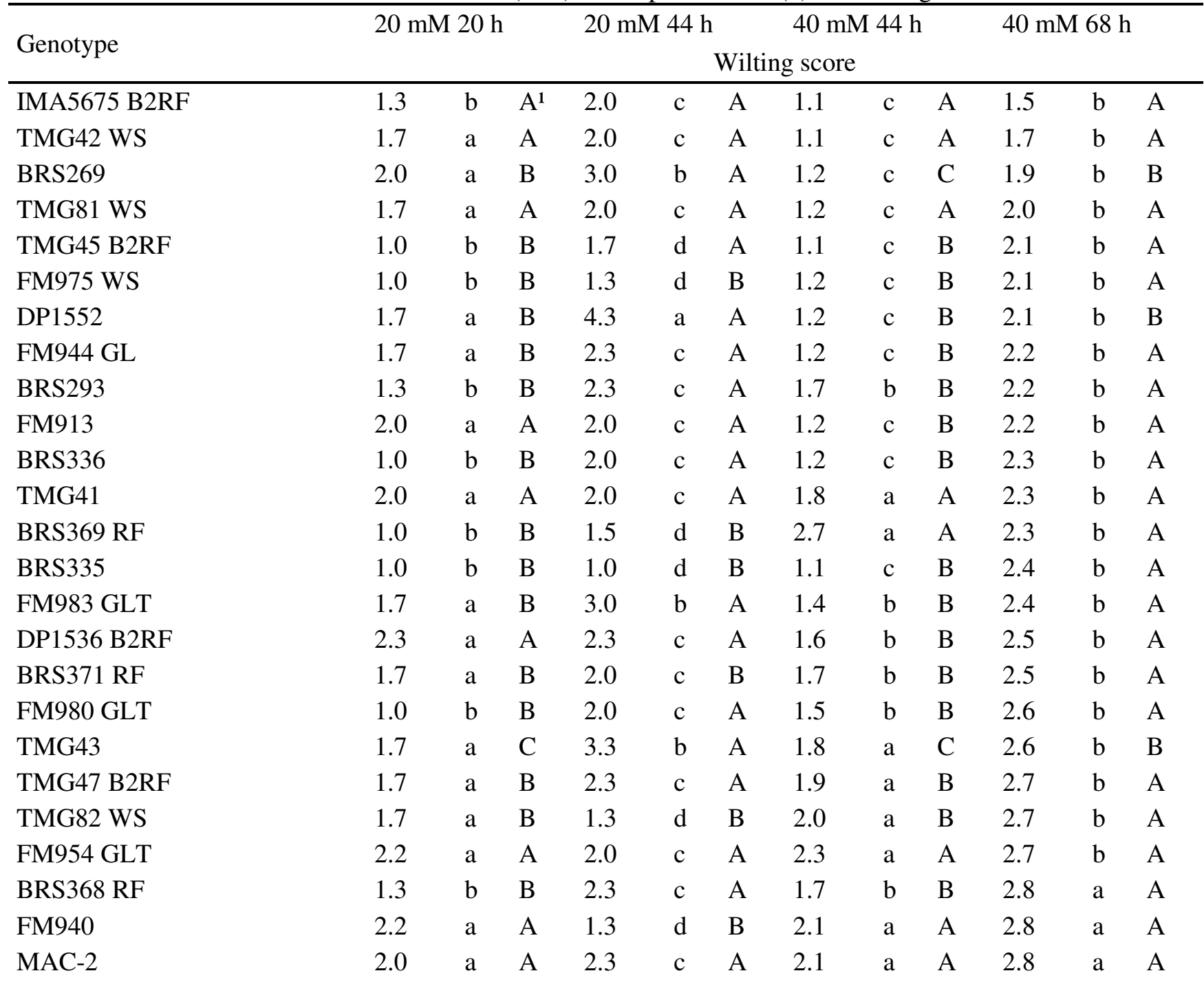




\begin{tabular}{|c|c|c|c|c|c|c|c|c|c|c|c|c|}
\hline IMA8276 WS & 1.5 & $\mathrm{~b}$ & B & 2.5 & $\mathrm{c}$ & $\mathrm{A}$ & 2.2 & $\mathrm{a}$ & A & 2.9 & $\mathrm{a}$ & A \\
\hline IAC25 & 2.0 & $\mathrm{a}$ & $\mathrm{B}$ & 2.0 & $\mathrm{c}$ & $\mathrm{B}$ & 2.2 & $\mathrm{a}$ & $\mathrm{B}$ & 3.2 & $\mathrm{a}$ & A \\
\hline IMA8405 GLT & 1.3 & $\mathrm{~b}$ & $\mathrm{C}$ & 1.3 & $\mathrm{~d}$ & $\mathrm{C}$ & 2.4 & $\mathrm{a}$ & B & 3.2 & $\mathrm{a}$ & A \\
\hline IMA2106 GL & 1.8 & $\mathrm{a}$ & B & 1.0 & $\mathrm{~d}$ & $\mathrm{C}$ & 2.0 & $\mathrm{a}$ & B & 3.2 & $\mathrm{a}$ & A \\
\hline IAC24 & 2.0 & $\mathrm{a}$ & B & 1.0 & $\mathrm{~d}$ & $\mathrm{C}$ & 2.3 & $\mathrm{a}$ & B & 3.3 & $\mathrm{a}$ & A \\
\hline TMG48 B2RF & 2.2 & $\mathrm{a}$ & B & 2.0 & $\mathrm{c}$ & $\mathrm{B}$ & 2.5 & $\mathrm{a}$ & B & 3.5 & $\mathrm{a}$ & A \\
\hline TMG11 & 1.7 & $\mathrm{a}$ & $\mathrm{B}$ & 2.0 & $\mathrm{c}$ & $\mathrm{B}$ & 2.4 & $\mathrm{a}$ & $\mathrm{B}$ & 3.6 & $\mathrm{a}$ & A \\
\hline TMG44 B2RF & 1.7 & $\mathrm{a}$ & $\mathrm{B}$ & 2.5 & $\mathrm{c}$ & $\mathrm{B}$ & 2.1 & $\mathrm{a}$ & $\mathrm{B}$ & 3.7 & $\mathrm{a}$ & $\mathrm{A}$ \\
\hline $\mathrm{CV}(\%)$ & 20.7 & & & & & & & & & & & \\
\hline $\mathrm{H}^{2}(\%)$ & 85.6 & & & & & & & & & & & \\
\hline
\end{tabular}

The genotypes were classified into two different groups after 68 hours at the concentration of $40 \mathrm{mM}$, with scores varying from 1.5 (IMA5675 B2RF) to 3.7 (TMG44 B2RF). Although genotype TMG44 B2RF demonstrated susceptibility by the straw test, correspondence between results of pathogen inoculation and the oxalic acid test was not evident and could not be corroborated. Evaluation after 44 hours of exposure at $20 \mathrm{mM}$, in turn, grouped the materials into four categories, with wilting scores from 1.0 (IMA2106 GL, IAC24 and BRS335) to 4.3 (DP1552).

The data on lesion size and disease severity, obtained after inoculation with the strains $\mathrm{ScC}$ and $\mathrm{ScS}$ by the straw test, did not correlated with the scores obtained by the oxalic acid method (Table 6). Pearson's coefficient indicated that the methods did not converge for the ranking of cotton resistant genotypes.

Table 6. Pearson's correlation coefficient for oxalic acid and straw test methods used for the evaluation of cotton genotypes resistance against $S$. sclerotiorum.

Oxalic acid method

Straw test method

Correlation

\begin{tabular}{llll}
\hline $20 \mathrm{mM} 20 \mathrm{~h}$ & $\mathrm{x}$ & Lesion*ScC & $-0.379^{\mathrm{ns}}$ \\
$20 \mathrm{mM} 44 \mathrm{~h}$ & $\mathrm{x}$ & Lesion*ScC & $-0.279^{\mathrm{ns}}$ \\
$40 \mathrm{mM} 44 \mathrm{~h}$ & $\mathrm{x}$ & Lesion*ScC & $0.065^{\mathrm{ns}}$ \\
$40 \mathrm{mM} 68 \mathrm{~h}$ & $\mathrm{x}$ & Lesion*ScC & $0.018^{\mathrm{ns}}$ \\
$20 \mathrm{mM} 20 \mathrm{~h}$ & $\mathrm{x}$ & Lesion*ScS & $0.000^{\mathrm{ns}}$ \\
$20 \mathrm{mM} 44 \mathrm{~h}$ & $\mathrm{x}$ & Lesion*ScS & $0.381^{\mathrm{ns}}$ \\
$40 \mathrm{mM} 44 \mathrm{~h}$ & $\mathrm{x}$ & Lesion*ScS & $-0.260^{\mathrm{ns}}$ \\
$40 \mathrm{mM} 68 \mathrm{~h}$ & $\mathrm{x}$ & Lesion*ScS & $-0.324^{\mathrm{ns}}$ \\
$20 \mathrm{mM} 20 \mathrm{~h}$ & $\mathrm{x}$ & Severity*ScC & $-0.302^{\mathrm{ns}}$ \\
$20 \mathrm{mM} 44 \mathrm{~h}$ & $\mathrm{x}$ & Severity*ScC & $-0.325^{\mathrm{ns}}$ \\
$40 \mathrm{mM} 44 \mathrm{~h}$ & $\mathrm{x}$ & Severity*ScC & $-0.010^{\mathrm{ns}}$ \\
$40 \mathrm{mM} 68 \mathrm{~h}$ & $\mathrm{x}$ & Severity*ScC & $0.059^{\mathrm{ns}}$ \\
$20 \mathrm{mM} 20 \mathrm{~h}$ & $\mathrm{x}$ & Severity*ScS & $-0.119^{\mathrm{ns}}$ \\
$20 \mathrm{mM} 44 \mathrm{~h}$ & $\mathrm{x}$ & Severity*ScS & $0.328^{\mathrm{ns}}$ \\
$40 \mathrm{mM} 44 \mathrm{~h}$ & $\mathrm{x}$ & Severity*ScS & $-0.310^{\mathrm{ns}}$ \\
$40 \mathrm{mM} 68 \mathrm{~h}$ & $\mathrm{x}$ & Severity*ScS & $-0.340^{\mathrm{ns}}$ \\
\hline
\end{tabular}

${ }^{\mathrm{ns}}$ Non-significant at 5\%. 


\section{DISCUSSION}

The unquestionable importance of the interaction pathogen $\mathrm{x}$ environment $\mathrm{x}$ host plant in the expression of resistance/susceptibility of the phenotype ( $\mathrm{P}=\mathrm{G}+\mathrm{E}+\mathrm{GxE})$ to a given disease, is reflected in the steps of selection of materials for future recommendation of cultivars. These variables were considered in this study. Ranking of Brazilian cotton genotypes resistant to white mold depended on differences between strains of $S$. sclerotiorum and on the incubation environments of inoculated seedlings.

White mold is a disease highly dependent on favorable environmental conditions for its occurrence, so much that adequate environment for the fungus also allows maximum differenciation between host plant genotypes. Therefore, the low correlation between field data and that of controlled conditions make it difficult to rank the genotypes for resistance against white mold (JULIATTI et al., 2013). Such discrepancy also can occur between results obtained in greenhouse with those of growth chambers. The same soybean genotype can be classified as resistant to completely susceptible to white mold (ZITO et al., 2006), thus, indication of selected materials is done after incubation in growth chamber (JULIATTI et al., 2014; CASTRO et al., 2016). Relative humidity and temperature are considered as the main limiting factors for evaluation of resistance of plants to S. sclerotiorum in greenhouses (BOLAND; HALL, 1987; ANTÔNIO et al., 2008; MILA; YANG, 2008), because they affect pathogen infection, especially in the first 24 to 72 hours after inoculation (PRATT; ROWE, 1991). Monitoring environment conditions in the present greenhouse study recorded maximum daily temperatures above the adequate level for fungal mycelia development $\left(18-25^{\circ} \mathrm{C}\right.$ ) (AGRIOS, 2005 ) and relative air moisture below $90 \%$ (Figure $3)$. High average temperature and low relative moisture recorded during the experiment could have affected pathogen development, resulting in reduced lesion size and, consequently lower disease severity. Therefore, it can be inferred that the environment in the growth chamber, similarly to what was observed for soybeans, is more adequate for evaluations of resistance against white mold among cotton genotypes. Along with a controlled environment, artificial inoculation is required to evaluate genotype response due to uniformity of inoculum deposition and subsequent infection (DAVAR et al., 2011). Standardization by the straw test assured the amount of inoculum in each plant, avoiding falsenegative results and allowed proper characterization of susceptibility of each material. Finally, considering plant stage development, inoculation at $\mathrm{V}_{2}$ reduces the time required for the screening of cotton genotypes for resistance against white mold. Moreover, early inoculation tends to highlight differences in genotypes that could be lessened with plant maturation (GARCIA; JULIATTI, 2012).

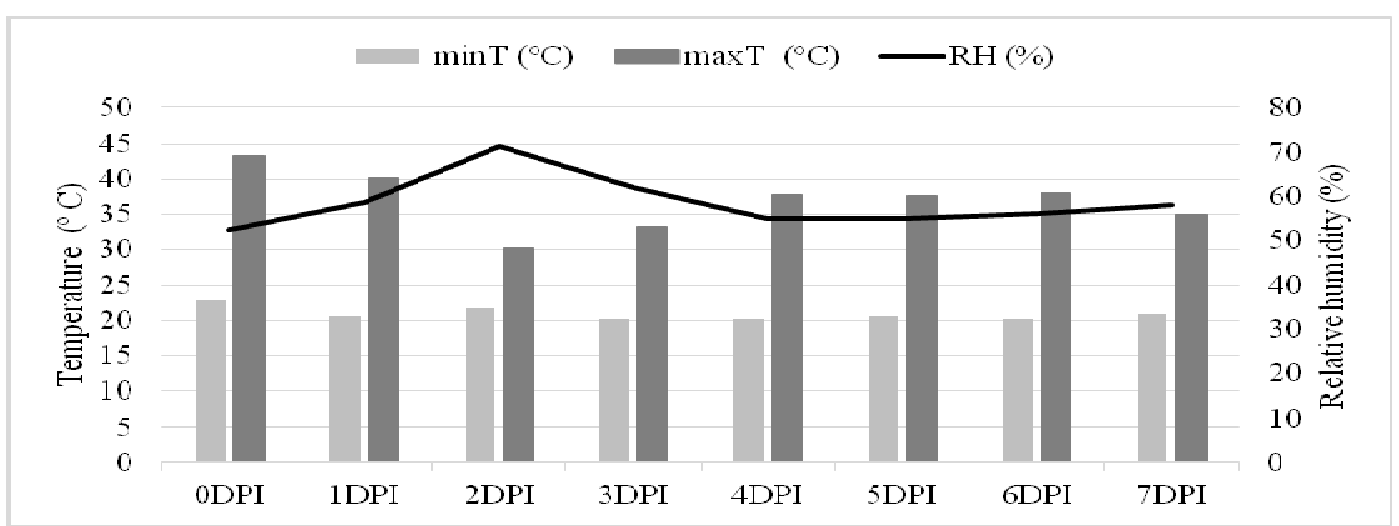

Figure 3. Meteorological data recorded in the greenhouse during the incubation period for cotton genotypes inoculated with S. sclerotiorum.

minT and maxT: minimum and maximum temperatures, respectively; RH: relative humidity; DPI: days post-inoculation.

Regardless of interferences in the incubation environment, the pathogen interacts with the genotypes in the expression of the phenotype. The greater aggressiveness of strain $\mathrm{ScC}$ was evident in the growth chamber, in comparison with strain $\mathrm{ScS}$, even though this had been described as highly aggressive to soybeans (GARCIA; JULIATTI,
2012). Variability in S. sclerotiorum aggressiveness, reported in common beans, sunflower and soybeans (PRICE; CALHOUN, 1975; IRANI et al., 2011; ZANCAN et al., 2015), is commonly observed among strains isolated from different hosts or from distant geographical regions (KULL et al., 2004; DAVAR et al., 2011) due to variation in effector 
production (CASTRO et al., 2016). Such variability is relevant since, in breeding programs, the use of more aggressive strains is recommended in order to identify greater resistance levels in the germplasm collection (ZANCAN et al., 2015). The result obtained in this study suggests a possible physiological specialization of S. sclerotiorum to its host, previously suggested (DAVAR et al., 2011) but still awaiting for omics studies about the interaction Sclerotinia-cotton to be confirmed.

Assuming that the factors of virulence or aggressiveness of $S$. sclerotiorum include the production of oxalic acid and of pectolytic enzymes (DUTTON; EVANS, 1996; ZHOU; BOLAND, 1999), quantitative differences in the synthesis of these factors would be related to aggressiveness of both strains evaluated. Moreover, the greater lignin content in cotton than in soybeans (on average, 1.4 fold greater in the former) (PELTIER; HATFIELD; GRAU, 2009; TUTUS; EZICI; ATES, 2010; KANG et al., 2012; GRIS et al., 2013), could reinforce the hypothesis of specificity. Thus, it is suggested that the strain obtained from soybeans $(\mathrm{ScS})$ synthesizes insufficient amounts of oxalic acid to degrade cotton cell wall. Consequently, colonization by the fungus is compromised. This hypothesis is supported by the lack of correlation between the results of the straw test with those of the oxalic acid assay. Possibly, solutions that are more concentrated would be required, in contrast to what was recommended for common beans and soybeans (KOLKMAN; KELLY, 2000; ANTÔNIO et al., 2008; HÜLLER et al., 2016; SOUZA et al., 2016). The inconsistency of the oxalic acid method discourages the indirect evaluation of cotton resistance to white mold, be it by need to optimize the technique or by the combination with other physiological mechanisms of resistance in cotton, such as biosynthesis of phytoalexins, shikimic acid, phenolic compounds or oxalate detoxification (BALDINI et al., 2002; CUNHA et al., 2010; DAVIDSON et al., 2016).

Resistance to white mold is quantitative (HOFFMAN et al., 2002; LU, 2003). Thus, considering lesion length and disease severity, no cotton genotypes presented complete resistance. Nevertheless, it was possible to observe considerable variability for partial resistance among the genotypes, including commercial ones, such as FM944 GL, which expressed the smallest lesion size and disease severity, contrasting with FM975 WS. Research with lineages of common beans, canola and soybeans, resistant to this pathogen has been studied; however, no sources of complete resistance have been identified, but only variability for partial resistance (ARAHANA et al., 2001; AHMADIFAR;
DALIL 2013; JULIATTI et al., 2013; ZANCAN et al., 2015).

The cotton genotypes used in this study had considerable differences in resistance to white mold. Among the 33 genotypes evaluated, IMA2106 GL, MAC-2, DP1552 and FM944 GL were considered the most resistant, while the genotypes BRS293, FM975 WS and TMG44 B2RF were the most susceptible. All others presented variable levels of partial resistance. Variations in susceptibility can be attributed mostly to genetic causes, since all plants were inoculated at the same phenological stage and under the same incubation conditions, minimizing the effect of environment factors. Morphological mechanisms of escape, such as plant architecture and canopy density, can contribute for resistance of the genotypes against white mold, but do not explain the differences found in this study, since the pathogen was placed in direct contact with the conducting vessels of the seedling stem in its early development stage. This implies that physiological mechanisms are involved in resistance. The association between physiological and morphological resistance could constitute a viable strategy to be explored in cotton breeding for resistance to white mold. Molecular, biochemical and anatomical (histological) studies are necessary to understand the differences between genotypes and to propose future crossings to obtain durable resistance.

Analyses of genetic diversity are fundamental for plant breeding, since they allow the identification of promising genitors for the crossings. This type of study also allows the confirmation of dissimilarity of genotypes in relation to several agricultural characteristics (CRUZ; REGAZZI; CARNEIRO, 2012), such as resistance to plant pathogens (CASTRO, 2015). The use of traits associated to multivariate techniques has been widely used for the quantification of genetic distance, and can be found for several crops, including cotton (CARVALHO et al., 2003; ARAÚJO et al., 2014; COUTINHO; GUIMARÃES; VIDAL, 2014; RESENDE et al., 2014; VIOLATTI, 2016; GILIO et al., 2017). The methods of hierarchical and optimization clustering are among the most used to evaluate dissimilarity among genotypes (CRUZ; REGAZZI; CARNEIRO, 2012). Differences between these methods oftentimes justify the need for more than one analysis to reach conclusions that are more reliable. Although, in this study, the methods UPGMA and Tocher's did not converge into the same number of groups, they allowed a clear distinction of genotype FM944 GL and of the genotypes FM975 WS, 
TMG44 B2RF and BRS293, validating the results obtained.

\section{CONCLUSIONS}

The most resistant genotypes to $S$. sclerotiorum were FM944 GL, MAC-2, IMA2106 GL and DP1552, which are promising for management in areas with history of white mold occurrence.

The most susceptible ones were cultivars FM975 WS, TMG44 B2RF and BRS293. The strain of $S$. sclerotiorum obtained from a cotton field $(\mathrm{ScC})$ was more aggressive, suggesting a possible physiological specialization.

No correlation was observed between the oxalic acid and straw test methods, requiring caution in indirect evaluation of resistance to rank the genotypes. Based on genetic parameters, the environment of the growth chamber provided more adequate conditions to evaluate resistance of cotton genotypes to white mold.

The multivariate analyses using UPGMA and Tocher's methods confirmed that the genotypes evaluated are divergent among themselves.

\section{ACKNOWLEDGMENTS}

This research was supported by the Coordenação de Aperfeiçoamento de Pessoal de Nível Superior - CAPES, Conselho Nacional de Desenvolvimento Científico e Tecnológico - CNPq, and Fundação de Amparo à Pesquisa do Estado de Minas Gerais - FAPEMIG. The authors would like to thank Fundação Chapadão for providing the $S$. sclerotiorum strain ScC. T.P. Morais acknowledges PPGA-UFU and CAPES for PNPD scholarship.

RESUMO: A expansão da cultura do algodoeiro para terras altas e irrigadas do Cerrado brasileiro, apesar da possibilidade de aumentar a produção de fibras, levou à ocorrência de doenças antes consideradas secundárias, como o mofo branco [Sclerotinia sclerotiorum (Lib.) de Bary]. A resistência genética do hospedeiro é de extrema importância nas estratégias de manejo integrado dessa doença. Avaliou-se a resistência de genótipos brasileiros de algodão, desafiados com diferentes isolados de S. sclerotiorum, sob duas condições de incubação para o progresso da doença. Além disso, foi avaliada a possível correlação entre os métodos do ácido oxálico e do straw test para ranquear os genótipos. A inoculação artificial foi realizada quando as plantas de algodoeiro atingiram o estágio fenológico $\mathrm{V}_{2}$, com fungos isolados de culturas comerciais de soja $(\mathrm{ScS})$ ou de algodão $(\mathrm{ScC})$ naturalmente infectadas. O controle consistiu de plantas inoculadas somente com meio de cultura. Após a inoculação, as plantas foram mantidas em câmara de crescimento ou em casa de vegetação durante uma semana e avaliadas quanto aos sintomas e severidade da doença. O teste do ácido oxálico consistiu na submersão da haste das plantas de algodão, após remoção das raízes, em uma solução de 20 ou $40 \mathrm{mM}$ por 20,44 ou 68 h. Uma escala visual de murcha foi usada para distinguir a sensibilidade dos genótipos ao ácido. Os dados foram submetidos à análise individual, conjunta e multivariada, agrupando os genótipos de algodoeiro pelo teste de Scott-Knott $(\mathrm{p}<0,05)$ e pelos métodos UPGMA e de Tocher. Diferença na agressividade entre os isolados foi identificada, na qual ScC resultou em maior severidade da doença. Isto sugere possível especialização físiológica de S. sclerotiorum para diferentes hospedeiros. Observou-se que o ambiente da câmara de crescimento proporcionou condições mais adequadas para infecção por $S$. sclerotiorum comparativamente à casa de vegetação, permitindo melhor seleção de genótipos resistentes. Os métodos de agrupamento UPGMA e Tocher confirmaram que os genótipos avaliados diferem entre si na resistência ao mofo branco. Não foi observada correlação entre o ácido oxálico e o straw test.

PALAVRAS-CHAVE: Gossypium hirsutum L. Sclerotinia sclerotiorum. Diversidade genética. Especialização fisiológica.

\section{REFERENCES}

ABAWI, G. S.; GROGAN, R. G. Epidemiology of diseases caused by Sclerotinia species. Phytopathology, v. 69, p. 899-904, 1979. https://doi.org/10.1094/Phyto-69-899

ABO-ELYOUSR, K. A. M.; HASHEM, M.; ALI, E. H. Integrated control of cotton root rot disease by mixing fungal biocontrol agents and resistance inducers. Crop Protection, v. 28, n. 4, p. 295-301, 2009.

https://doi.org/10.1016/j.cropro.2008.11.004

ABRAPA - Associação Brasileira dos Produtores de Algodão. Exportação Mundial de Algodão. 2017. Disponível em: http://www.abrapa.com.br/Paginas/dados/exportacao-mundial-algodao_backup2017.aspx. Acesso em: 09 fev. 2018. 
ABREU, M. J. de. Reação de genótipos de feijão e agressividade de isolados do agente causal do mofobranco. 2016. 72 f. Tese (Doutorado em Genética e Melhoramento de Plantas) - Universidade Federal de Lavras, Lavras, 2016.

ACHBANI, E. H.; DE LABROUHE, D. T.; VEAR, F. Methods of determining the reaction of sunflower genotypes to terminal bud attack by Sclerotinia sclerotiorum (Lib) de Bary. Agronomie, v. 14, n. 3, p. 195203, 1994. https://doi.org/10.1051/agro:19940306

AGRIOS, G. N. Plant pathology. 5. ed. San Diego: Academic Press, 2005. 922 p.

AHMADIFAR, M.; DALIL, A. Evaluation of rapeseed genotypes resistance to Sclerotinia sclerotiorum (Lib.) de Bary. American-Eurasian Journal of Agricultural \& Environmental Sciences, v. 13 n. 4, p. 517-520, 2013.

AKEM, C. N.; BELLAR, M.; BAYAA, B. Comparative growth and pathogenicity of geographical isolates of Sclerotinia sclerotiorum on lentil genotypes. Plant Pathology Journal, v. 5, n. 1, p. 67-71, 2006. https://doi.org/10.3923/ppj.2006.67.71

AKEM, C. N.; MELOUK, H. A.; SMITH, O. D. Field evaluation of peanut genotypes for resistance to Sclerotinia blight. Crop Protection, v. 11, n. 4, p. 345-348, 1992. https://doi.org/10.1016/02612194(92)90061-9

ANTÔNIO, R. P.; SANTOS, J. B.; SOUZA, T. P.; CARNEIRO, F. F. Genetic control of the resistance of common bean to white mold using the reaction to oxalic acid. Genetics and Molecular Research, v. 7, p. 733740, 2008. http://dx.doi.org/10.4238/vol7-3gmr466

ARAHANA, V. S.; GRAEF, G. L.; SPECHT, J. E.; STEADMAN, J. R.; ESKRIDGE, K. M. Identification of QTLs resistance to Sclerotinia sclerotiorum in soybean. Crop Science, v. 41, n. 1, p. 180-188, 2001. https://doi.org/10.2135/cropsci2001.411180x

ARAÚJO, L. F. de; ALMEIDA, W. S.; BERTINI, C. H. C. M.; VIDAL NETO, F. C.; BLEICHER, E. The use of different clustering methods in the evaluation of genetic diversity in upland cotton. Revista Ciência Agronômica, v. 45, n. 2, p. 312-318, 2014. https://doi.org/10.1590/S1806-66902014000200012

BALDINI, M.; TURI, M.; VISCHI, M.; VANNOZZI, G. P.; OLIVIERI, A. M. Evaluation of genetic variability for Sclerotinia sclerotiorum (Lib.) de Bary resistance in sunflower and utilization of associated molecular markers. Helia, v. 25, n. 36, p. 177-190, 2002. https://doi.org/10.2298/HEL0236177B

BASTIEN, M.; SONAH, H.; BELZILE, F. Genome wide association mapping of Sclerotinia sclerotiorum resistance in soybean with a genotyping-by-sequencing approach. The Plant Genome, v. 7, n. 1, p. 1-13, 2014. https://doi.org/10.3835/plantgenome2013.10.0030

BELTRÃO, N. E. M.; AZEVEDO, D. M. P. Agronegócio do algodão no Brasil. 2. ed. v. 2. Brasília: Embrapa, 2008. 1309 p.

BOLAND, G. J.; HALL, R. Evaluating soybean cultivars for resistance to Sclerotinia sclerotiorum under field conditions. Plant Disease, v. 71, n. 1, p. 934-936, 1987. https://doi.org/10.1094/PD-71-0934

BOLAND, G. J.; HALL, R. Index of plant hosts of Sclerotinia sclerotiorum. Canadian Journal of Plant Pathology, v. 16, p. 93-108, 1994. https://doi.org/10.1080/07060669409500766

CAO, J.; XU, Y.; CAI, X. TMT-based quantitative proteomics analyses reveal novel defense mechanisms of Brassica napus against the devastating necrotrophic pathogen Sclerotinia sclerotiorum. Journal of Proteomics, v. 143, p. 265-277, 2016. https://doi.org/10.1016/j.jprot.2016.03.006 
CARVALHO, L. P.; LANZA, M. A.; FALLIERI, J.; SANTOS, J. W. Análise da diversidade genética entre acessos de banco ativo de germoplasma de algodão. Pesquisa Agropecuária Brasileira, v. 38, n. 10, p. 11491155, 2003. https://doi.org/10.1590/S0100-204X2003001000003

CASTRO, L. H. S.; AGUIAR, L. H. M.; LERNES, E. M.; SILVA JÚNIOR, E. G.; REIS, M. C.; GOMES, B. C.; FERREIRA, J. F. M.; CARDOSO, D. B.; SOUZA, L. B. Avaliação da resistência de genótipos de algodoeiro branco e colorido à Sclerotinia sclerotiorum pelo método straw test. In: CONGRESSO BRASILEIRO DO ALGODÃO, 7, 2016. Foz do Igaçú. Anais... Brasília: Embrapa, 2016. p. 541.

CASTRO, L. H. S. Resistência de genótipos de soja a isolados de Sclerotinia sclerotiorum em casa de vegetação e câmara de crescimento. 2015. 58 f. Dissertação (Mestrado em Agronomia/Fitopatologia) Universidade Federal de Uberlândia, Uberlândia, 2015.

CHARCHAR, M. C. D.; ANJOS, J. R. N.; OSSIPI, E. Ocorrência de nova doença do algodoeiro irrigado no Brasil, causada por Sclerotinia sclerotiorum. Pesquisa Agropecuária Brasileira, v. 34, p. 1101-1106, 1999. https://doi.org/10.1590/S0100-204X1999000600024

CHITARRA, L. G. Mofo branco em algodoeiro. Campina Grande: Embrapa Algodão, 2007. 3 p. (Comunicado Técnico, 336).

CHITARRA, L. G. Poder destrutivo (mofo branco em algodoeiro). Cultivar, v. 6, p. 36-38, 2008.

COUTINHO, T. C.; GUIMARÃES, M. A.; VIDAL, M. S. Determinação da diversidade genética entre acessos de algodão por meio de marcadores microssatélites. Bioscience Journal, v. 30, n. 5, p. 1447-1458, 2014.

CRUZ, C. D.; REGAZZI, A. J.; CARNEIRO, P. C. S. Modelos biométricos aplicados ao melhoramento genético. Viçosa: UFV, 2012. 514 p.

CUNHA, W. G.; TINOCO, M. L. P.; PANCOTI, H. L.; RIBEIRO, R. E.; ARAGAO, F. J. L. High resistance to Sclerotinia sclerotiorum in transgenic soybean plants transformed to express an oxalate decarboxylase gene. Plant Pathology, v. 59, p. 654-660, 2010. https://doi.org/10.1111/j.1365-3059.2010.02279.x

DAVAR, R.; DARVISHZADEH, R.; MAJD, A.; GOUSTA, Y.; SARRAFI, A. QTL mapping of partial resistance to basal stem rot in sunflower using recombinant inbred lines. Phytopathologia Mediterranea, v. 49, n. 3, p. 330-341, 2011.

DAVIDSON, A. L.; BLAHUT-BEATTY, L.; ITAYA, A.; ZHANG, Y.; ZHENG, S.; SIMMONDS, D. Histopathology of Sclerotinia sclerotiorum infection and oxalic acid function in susceptible and resistant soybean. Plant Pathology, v. 65, n. 6, p. 878-887, 2016. https://doi.org/10.1111/ppa.12514

DUTTON, M. V.; EVANS, C. S. Oxalate production by fungi: its role in pathogenicity and ecology in the soil environment. Canadian Journal of Microbiology, v. 42, n. 9, p. 881-895, 1996. https://doi.org/10.1139/m96114

FISCHER, I. H.; FILETTI, M. D. S.; CRUZ, J. C. S.; BUENO, C. J. Efeito da temperatura e reação de genótipos de quiabeiro ao mofo branco. Summa Phytopathologica, v. 40, p. 49-53, 2014.

https://doi.org/10.1590/S0100-54052014000100007

FREI, M. Lignin: characterization of a multifaceted crop component. The Scientific World Journal. 2013, 25 p.

GARCIA, R. A.; JULIATTI, F. C. Ranking of soybean genotypes with partial resistance from different inoculation methods of Sclerotinia sclerotiorum and correlation analysis between procedures. Tropical Plant Pathology, v. 37, p. 196-203, 2012. https://doi.org/10.1590/S1982-56762012000300006 
GARG, H.; LI, H.; SIVASITHAMPARAM, K.; BARBETTI, M. J. Differentially expressed proteins and associated histological and disease progression changes in cotyledon tissue of a resistant and susceptible genotype of Brassica napus infected with Sclerotinia sclerotiorum. PLoS One, v. 8, n. 6, p. e65205, 2013. https://doi.org/10.1371/journal.pone.0065205

GARG, H.; LI, H.; SIVASITHAMPARAM, K.; KUO, J.; BARBETTI, M. J. The infection processes of Sclerotinia sclerotiorum in cotyledon tissue of a resistant and a susceptible genotype of Brassica napus. Annals of Botany, v. 106, n. 6, p. 897-908, 2010. https://doi.org/10.1093/aob/mcq196

GILIO, T. A. S.; ARAÚJO, D. V.; KRAUSE, W.; ROSA, H. H. R.; ASCARI, J. P. Genetic divergence among cotton genotypes grown in the main season and off season. Revista Caatinga, v. 30, n. 2, p. 377-390, 2017. https://doi.org/10.1590/1983-21252017v30n213rc

GRIS, C. F.; PINHO, E. V. R. V.; CARVALHO, M. L. M.; DINIZ, R. P.; ANDRADE, T. Lignificação da planta e qualidade de sementes de soja RR pulverizadas com herbicida glifosato. Revista Ceres, v. 60, n. 2, p. 286-292, 2013. https://doi.org/10.1590/S0034-737X2013000200019

HOFFMAN, D. D.; DIERS, B. W.; HARTMAN, G. L.; NICKELL, C. D.; NELSON, R. L.; PEDERSEN, W. L.; COBER, E. R., GRAEF, G. L.; STEADMAN, J. R.; GRAU, C. R.; NELSON, B. D.; DEL RIO, L. E.; HELMS, T.; ANDERSON, T.; POYSA, V.; RAJCAN, I.; AND STIENSTRA, W. C. Selected soybean plant introductions with partial resistance to Sclerotinia sclerotiorum. Plant Disease, v. 86, n. 9, p. 971-980, 2002. https://doi.org/10.1094/PDIS.2002.86.9.971

HÜLLER, G. C.; JACCOUD FILHO, D. S.; PIERRE, M. L. C.; TULLIO, H. E.; GRABICOSKI, E. M. G.; JULIATTI, F. C. Different methods of assessing susceptibility of soybean genotypes to white mold. Bioscience Journal, v. 32, n. 2, p. 389-402, 2016. https://doi.org/10.14393/BJ-v32n2a2016-31365

IQUIRA, E.; HUMIRA, S.; FRANÇOIS, B. Association mapping of QTLs for Sclerotinia stem rot resistance in a collection of soybean plant introductions using a genotyping by sequencing (GBS) approach. BMC Plant Biology, v. 15, n. 5, p. 1-12, 2015. https://doi.org/10.1186/s12870-014-0408-y

IRANI, H.; HEYDARI, A.; JAVAN-NIKKHAH, M.; IBRAHIMOV, A. S. Pathogenicity variation and mycelial compatibility groups in Sclerotinia sclerotiorum. Journal of Plant Protection Research, v. 51, n. 4, p. 329-336, 2011. https://doi.org/10.2478/v10045-011-0054-4

JOSHI, R. K.; MEGHA, S.; RAHMAN, M. H.; BASU, U.; KAV, N. N. A global study of transcriptome dynamics in canola (Brassica napus L.) responsive to Sclerotinia sclerotiorum infection using RNA-Seq. Gene, v. 590, n. 1, p. 57-67, 2016a. https://doi.org/10.1016/j.gene.2016.06.003

JOSHI, R. K.; MEGHA, S.; BASU, U.; RAHMAN, M. H.; KAV, N. N. Genome wide identification and functional prediction of long non-coding RNAs responsive to Sclerotinia sclerotiorum infection in Brassica napus. PLoS One, v. 11, n. 7, p. e0158784, 2016b. https://doi.org/10.1371/journal.pone.0158784

JULIATTI, F. C.; CAIRES, A. M.; JULIATTI, B. C. M.; BORIN, M. R.; SOUZA FILHO, D. J. Reação de genótipos de soja transgênicos e convencionais à podridão branca da haste. Bioscience Journal, v. 4, n. 4, p. 921-931, 2013.

JULIATTI, F. C.; SAGATA, E.; JACCOUD FILHO D. S.; JULIATTI, B. C. M. Métodos de inoculação e avaliação da resistência de genótipos de soja à Sclerotinia sclerotiorum. Bioscience Journal, v. 30, n. 4, p. 958-968, 2014.

KANG, S.; XIAO, L.; MENG, L.; ZHANG, X.; SUN, R. Isolation and structural characterization of lignin from cotton stalk treated in an ammonia hydrothermal system. International Journal of Molecular Sciences, v. 13, n. 11, p. 15209-15226, 2012. https://doi.org/10.3390/ijms131115209 
KOLKMAN, J. M.; KELLY, J. D. An indirect test using oxalate to determine physiological resistance to white mold in common bean. Crop Science, v. 40, p. 281-285, 2000. https://doi.org/10.2135/cropsci2000.401281x

KULL, L. S.; PEDERSEN, W. L.; PALMQUIST, D.; HARTMAN, G. L. Mycelial compatibility grouping and aggressiveness of Sclerotinia sclerotiorum. Plant Disease, v. 88 n. 4, p. 325-332, 2004.

https://doi.org/10.1094/PDIS.2004.88.4.325

LEITE, M. E. Seleção recorrente em feijoeiro visando resistência à Sclerotinia sclerotiorum e respostas bioquímicas associadas à defesa contra o patógeno. 2014. $154 \mathrm{f}$. Tese (Doutorado em Genética e Melhoramento de Plantas) - Universidade Federal de Lavras, Lavras, 2014.

LU, G. Engineering Sclerotinia sclerotiorum resistance in oilseed crops. African Journal of Biotechnology, v. 2, n. 12, p. 509-516, 2003. https://doi.org/10.5897/AJB2003.000-1101

MARUR, C. J.; RUANO, O. A reference system for determination of developmental stages of upland cotton. Revista de Oleaginosas e Fibrosas, v. 5, n. 2, p. 313-317, 2001.

MILA, A. L.; YANG, X. B. Effects of fluctuating soil temperature and water potential on sclerotia germination and apothecial production of Sclerotinia sclerotiorum. Plant Disease, v. 92, n. 1, p. 78-82, 2008.

https://doi.org/10.1094/PDIS-92-1-0078

NOGUEIRA, A. P. O. Correlações, análise de trilha e diversidade fenotípica e molecular em soja. 2011. 139 f. Tese (Doutorado em Genética e Melhoramento de Plantas) - Universidade Federal de Viçosa, Viçosa, 2011.

OLIVEIRA, M. B.; ANDRADE, R. V.; GROSSI-DE-SÁ, M. F.; PETROFEZA, S. Analysis of genes that are differentially expressed during the Sclerotinia sclerotiorum-Phaseolus vulgaris interaction. Frontiers in Microbiology, v. 6, p. 1162, 2015. https://doi.org/10.3389/fmicb.2015.01162

PELTIER, A. J.; HATFIELD, R. D.; GRAU, C. R. Soybean stem lignin concentration relates to resistance to Sclerotinia sclerotiorum. Plant Disease, v. 93, p. 49-154, 2009. https://doi.org/10.1094/PDIS-93-2-0149

PELUFFO, L.; LIA, V.; TROGLIA, C.; MARINGOLO, C.; NORMA, P.; ESCANDE, A.; HOPP, E. H.; LYTOVCHENKO, A.; FERNIE, A.R.; HEINZ, R.; CARRARI, F. Metabolic profiles of sunflower genotypes with contrasting response to Sclerotinia sclerotiorum infection. Phytochemistry, v. 71, n. 1, p. 70-80, 2010. https://doi.org/10.1016/j.phytochem.2009.09.018

PETZOLDT, R.; DICKSON, M. H. Straw test for resistance to white mold in beans. Annual Report of the Bean Improvement Cooperative, v. 39, p. 142-143, 1996.

PORTER, L. D.; HOHEISEL, G.; COFFMAN, V. A. Resistance of peas to Sclerotinia sclerotiorum in the Pisum core collection. Plant Pathology, v. 58, n. 1, p. 52-60, 2009. https://doi.org/10.1111/j.13653059.2008.01937.x

PRATT, R. G.; ROWE, D. E. Differential responses of alfalfa genotypes to stem inoculations with Sclerotinia sclerotiorum and S. trifoliorum. Plant Disease, v. 75, n. 2, p. 188-191, 1991. https://doi.org/10.1094/PD-750188

PRICE, K.; CALHOUN, J. Pathogenicity of isolates of Sclerotinia sclerotiorum (Lib.) de Bary to several hosts. Phytopathology, v. 83, p. 232-238, 1975. https://doi.org/10.1111/j.1439-0434.1975.tb03534.x

RAMALHO, M. A. P.; ABREU, A. F. B.; SANTOS, J. B.; NUNES, J. A. R. Aplicações da genética quantitativa no melhoramento de plantas autógamas. Lavras: Editora UFLA, 2012. 522 p.

RAO, R. C. Advanced statistical methods in biometric research. New York: John Wiley, 1952. 390 p. 
RESENDE, M. A. V. de; FREITAS, J. A. de; LANZA, M. A.; RESENDE, M. D. V. de; AZEVEDO, C.F. Divergência genética e índice de seleção via BLUP em acessos de algodoeiro para características tecnológicas da fibra. Pesquisa Agropecuária Tropical, v. 44, n. 3, p. 334-340, 2014. https://doi.org/10.1590/S198340632014000300006

RODRIGUES, E.; SCHWAN-ESTRADA, K. R. F.; FIORI-TUTIDA, A. C. G.; STANGARLIN, J. R.; CRUZ, M. E. S. Fungitoxicidade, atividade elicitora de fitoalexinas e proteção de alface em sistema de cultivo orgânico contra Sclerotinia sclerotiorum pelo extrato de gengibre. Summa Phytopathologica, v. 33, n. 2, p. 124-128, 2007. https://doi.org/10.1590/S0100-54052007000200004

SABATO, E. O.; TEIXEIRA, F. F. Processos para avaliação da resistência genética de genótipos de milho aos enfezamentos causados por molicutes. Sete Lagoas: Embrapa Milho e Sorgo, 2015. 8 p. (Embrapa Milho e Sorgo. Circular Técnica, 210).

SCHWAN-ESTRADA, K. R. F.; STANGARLIN, J. R.; PASCHOLATI, S. F. Mecanismos bioquímicos de defesa vegetal. In: PASCHOLATI, S. F.; LEITE, B.; STANGARLIN, J. R.; CIA, P. (Eds). Interação planta patógeno: fisiologia, bioquímica e biologia molecular. Piracicaba: FEALQ, 2008. p. 227-248.

SIMON, G. A.; KAMADA, T.; MOITEIRO, M. Divergência genética em milho de primeira e segunda safra. Semina: Ciências Agrárias, v. 33, n. 2, p. 449-458, 2012. https://doi.org/10.5433/1679-0359.2012v33n2p449

SINGH, P. S.; TERÁN, H. Evolution of screening methods for detection of physiological resistance to White mold in common bean. Annual Report of the Bean Improvement Cooperative, v. 51, p. 40-41, 2008.

SNA - Sociedade Nacional de Agricultura. Perdas nas lavouras por causa do mofo branco podem chegar a 30\%. 2014. Disponível em: http://sna.agr.br/perdas-nas-lavouras-por-causa-do-mofo-branco-podem-chegar-a30/. Acesso em: 13 fev. 2018.

SOUZA, D. A.; BALESTRE, M.; PAMPLONA, A. K.; LEITE, M. E.; DIAS, J. A.; SANTOS, J. B. White mold resistance-associated quantitative trait loci in the Jalo x Small White common bean population. Genetics and Molecular Research, v. 15, n. 3 p. 1-15, 2016. https://doi.org/10.4238/gmr.15038724

STANGARLIN, J. R.; KUHN, O. J.; TOLEDO, M. V.; PORTZ, R. L.; SCHWAN-ESTRADA, K. R. F.; PASCHOLATI, S. F. A defesa vegetal contra fitopatógenos. Scientia Agraria Paranaensis, v. 10, n. 1, p. 1846, 2011.

SUASSUNA, N. Ataque branco. Goiânia: Promoalgo. v. 8, n. 143, 2012. 8 p.

SUASSUNA, N. D.; COUTINHO W. M. Manejo das principais doencas do algodoeiro no Cerrado brasileiro. In: FREIRE, E. C. (Ed.). Algodão no Cerrado do Brasil. Brasília: Associação Brasileira dos Produtores de Algodão, 2007. p. 479-521.

TERÁN, H.; LEMA, M.; SCHWARTZ, H. F.; DUNCAN, R.; GILBERTSON, R.; SINGH, S. P. Modified Petzoldt and Dickson scale for white mold rating of common bean. Annual Report of the Bean Improvement Cooperative, v. 49, p. 115-116, 2006.

TUTUS, A.; EZICI, A. C.; ATES, S. Chemical, morphological and anatomical properties and evaluation of cotton stalks (Gossypium hirsutum L.) in pulp industry. Scientific Research and Essays, v. 5, n. 12, p. 1553$1560,2010$.

VIOLATTI, M. R. Qualidade da fibra e diversidade genética em algodoeiro de fibra branca. 2016. 44 f. Dissertação (Mestrado em Fitotecnia) - Universidade Federal de Uberlândia, Uberlândia, 2016.

WEGULO, S. N.; YANG, X. B.; MARTINSON, C. A. Soybean cultivar responses to Sclerotinia sclerotiorum in field and controlled environment studies. Plant Disease, v. 82, p. 1264-1270, 1998. 
WEI, W.; MESQUITA, A. C. O.; FIGUEIRÓ, A. A.; WU, X.; MANJUNATHA, S.; WICKLAND, D. P.; HUDSON, M.E.; JULIATTI, F.C.; CLOUGH, S. J. Genome-wide association mapping of resistance to a Brazilian isolate of Sclerotinia sclerotiorum in soybean genotypes mostly from Brazil. BMC Genomics, v. 18, n. 1, p. 849, 2017.

WU, J.; CAI, G.; TU, J.; LI, L.; LIU, S.; LUO, X.; ZHOU, L.; FAN, C.; ZHOU, Y. Identification of QTLs for resistance to Sclerotinia stem rot and BnaC.IGMT5. $a$ as a candidate gene of the major resistant QTL SRC6 in Brassica napus. PloS One, v. 8, n. 7, p. e67740, 2013.

WU, J.; ZHAO, Q.; YANG, Q.; LIU, H.; LI, Q.; YI, X.; CHENG, Y.; GUO, L.; FAN, C.; ZHOU, Y. Comparative transcriptomic analysis uncovers the complex genetic network for resistance to Sclerotinia sclerotiorum in Brassica napus. Scientific Reports, v. 6, p. 19007, 2016.

ZANCAN, W. L. A.; STEADMAN, J. R.; HIGGINS, R.; JHALA, R.; MACHADO, J. C. Genetic and aggressiveness variation among Sclerotinia sclerotiorum dry bean isolates from Brazil fields. Bioscience Journal, v. 31, p. 1143-1151, 2015.

ZHOU, T.; BOLAND, G. J. Mycelial growth and production of oxalic acid by virulent and hypovirulent isolates of Sclerotinia sclerotiorum. Canadian Journal of Plant Pathology, v. 21, n. 1, p. 93-99, 1999.

ZITO, R. K.; WRUCK, D. S. M.; FRONZA, V.; ARANTES, N. E. Reação de genótipos de soja à Sclerotinia sclerotiorum. In: REUNIÃO DE PESQUISA DE SOJA DA REGIÃO CENTRAL DO BRASIL, 27, 2005 , Cornélio Procópio. Anais... Cornélio Procópio: Embrapa Soja, 2006. p. 362. 